\author{
DOI: 10.12731/wsd-2018-3-100-147 \\ УДК 616.34-008
}

\title{
АФФЕКТИВНЫЕ И ТРЕВОЖНЫЕ НАРУШЕНИЯ В КОЛОПРОКТОЛОГИЧЕСКОЙ ПРАКТИКЕ (НАУЧНЫЙ ОБЗОР)
}

\author{
Беккер Р.А., Быков Ю.В.
}

Цель исследования: Представить читателю подробный обзор распространённости аффективных и тревожных нарушений в колопроктологической практике, а также коморбидных с депрессивными и тревожными нарушенияли колопроктологических заболеваний (в частности, таких типичных для депрессии, как хронические запоры), гипотезы о механизмах двусторонней патофизиологической связи депрессивных и тревожных нарушений с колопроктологическими заболеваниями, а также обзор того, как психотропные лекарства могут влиять на функцию толстой кишки в положительную (терапевтически полезную) или отрицательную (способствуюшую колопроктологическим заболеваниям) сторону, и как традиционно применяемые в колопроктологии лекарства и методы лечения могут, в свою очередь, влиять на состояние психики в обе стороны, и представить вытекающие из этого стратегии одновременного лечения как психических, так и колопроктологических заболеваний.

Методология проведения работы: Авторами был проведён поиск литературы о связи колопроктологических заболеваний, таких, как болезнь Крона, неспецифический язвенный колит, запоры, анальные трещины и др., с депрессивными и тревожными состояниями, с использованием соответствующих ключевых слов, в поисковых системах PubMed u Google Scholar. Затем авторами был проведён поиск литературы о психиатрических осложнениях применяемых в колопроктологии лекарств и методов лечения и о применении их с терапевтическими целями в психиатрии, а также о применении антидепрессантов, анксиолитиков и других психотропных лекарств в колопроктологии.

Результаты: Полученные в результате этого обзора данные свидетельствуют о тесной двусторонней связи депрессивных и тревожных состояний с функиией толстого кишечника и с иельмм рядом колопроктологических заболеваний, а также о перспективности использования 
некоторых колопроктологических лекарств и методов лечения (например, антицитокиновых препаратов, пробиотиков, аминосалицилатов, трансплантации фекальной микробиоты) в психиатрии, а психотропных лекарств - при ряде колопроктологических заболеваний, и о необходимости уделять большее внимание выявлению и лечению коморбидных депрессивных и тревожных состояний у колопроктологических больных, и колопроктологических проблем, таких, как хронические запоры или дисбактериоз кишечника, у депрессивных и тревожных больных.

Область применения результатов: Полученные нами данные заслуживают самого широкого применения как в колопроктологической, так и в психиатрической практике.

Ключевые слова: депрессия; тревога; запоры; геморрой; воспалительные заболевания кишечника; злокачественные опухоли кишечника; анизм; ичитокины; дисбактериоз кишечника; пробиотики; антицитокиновая терапия; аминосалицилаты;; трансплантация фекальной микробиотьы.

\section{AFFECTIVE AND ANXIETY DISORDERS IN COLOPROCTOLOGY (SCIENTIFIC REVIEW)}

\section{Bekker R.A., Bykov Yu.V.}

Purpose: To provide the reader with a detailed overview of the prevalence of affective and anxiety disorders in coloproctology, as well as prevalence of comorbid coloproctology diseases in psychiatry (like constipation in depression), to present modern hypotheses about mechanisms of such bidirectional connection, and to describe how psychotropic medications can be useful in coloproctology and how traditional coloproctology drugs and treatment methods (probiotics, aminosalicylates, anticytokines, fecal microbiota transplantation) can be useful in psychiatry.

Methodology: We have searched the PubMed and Google Scholar search engines for relevant terms to find articles on the link of the coloproctology diseases with depressive and anxiety states and vice versa. Then we have searched PubMed and Google Scholar for literature on antidepressants in coloproctology and on probiotics, anticytokines, fecal microbiota transplantation and antiinflammatory agents in psychiatry.

Results: The data obtained by us indicate a close two-way link between depressive and anxiety states and a number of coloproctologic diseases, and 
with the function of the large intestine in general. The results also indicate a great potential for antidepressants in coloproctology and for probiotics and anticytokines and fecal microbiota transplantation in psychiatry. There is also a great need to improve diagnostics and treatment of comorbidity in both directions: comorbid coloproctology diseases in psychiatry and comorbid depressive and anxiety disorders in coloproctology.

Practical implications: The data obtained by us deserve the widest application both in coloproctology and in psychiatry.

Keywords: depressive disorders; anxiety disorders; constipation; hemorrhoids; inflammatory bowel disease; intestinal tumors; anismus; cytokines; intestinal dysbacteriosis; probiotics; anticytokine therapy; aminosalicylates; fecal microbiota transplantation.

\section{Обоснование актуальности}

По данным литературы, заболевания прямой кишки (ПК) и толстой кишки (ТК) или области ануса (воспалительные, онкологические и другие) часто сопровождаются аффективными и тревожными нарушениями, а также длительно не проходящей дисфункцией ЖКТ, как связанной с самим заболеванием, так и связанной с лечением и его побочными эффектами (ПЭ) [Thong MS et al, 2011; Bentzen AG et al, 2013].

Так, в частности, при лечении рака прямой и толстой кишки (РПТК) наиболее часто применяемые методы лечения включают в себя ионизирующее облучение, химиотерапию, хирургическое вмешательство и, иногда, также иммунотерапию (применение моноклональных антител) [Benedict $\mathrm{C}$ et al, 2016]. Все эти методы лечения имеют множество ПЭ, среди которых, в частности, описаны негативные психологические реакции (в том числе аффективные и тревожные нарушения), нарушения сексуальной функции, общее снижение качества жизни, длительно (более года) сохраняющаяся после лечения дисфункция ЖКТ и др. [Emmertsen KJ, Laurberg S, 2013; Taylor C, Bradshaw E, 2013; Fingeret MC et al, 2014]. Всё это усугубляет и без того тяжёлое состояние таких пациентов и снижает их приверженность к лечению. В свете этого, психологическое и психиатрическое обследование таких пациентов на предмет возможного наличия у них аффективных и тревожных расстройств, является важной клинической проблемой [Benedict $\mathrm{C}$ et al, 2016].

С другой же стороны, достаточно давно известно и о том, что и наоборот, сами по себе аффективные и тревожные нарушения и хронический психоэмоциональный стресс, нередко сопровождаются выраженными на- 
рушениями со стороны ЖКТ. Известна, в частности, классическая «триада Протопопова» соматовегетативных признаков депрессии, в которую входят, наряду с тахикардией и мидриазом, также хронические спастические запоры [Gupta RK, 2009]. А тревожные состояния и панические атаки (ПА) часто сопровождаются тенденцией к поносам или тенезмам (непродуктивным позывам в туалет) [Gupta RK, 2009].

Клинические исследования также систематически показывают, что депрессивные и тревожные состояния, хронический психоэмоциональный стресс, часто приводят к развитию или усугубляют уже имеющиеся проявления таких функциональных расстройств ЖКТ, как функциональная диспепсия (ФД) и синдром раздражённого кишечника (СРК) [Devanarayana NM et al, 2011; Vanuytsel T et al, 2014]. Верно и обратное: упомянутые функциональные расстройства ЖКТ часто сопровождаются коморбидными депрессивными и тревожными состояниями [Devanarayana NM et al, 2011; Vanuytsel T et al, 2014].

Также аффективные и тревожные расстройства, по данным множества исследований, повышают риск возникновения злокачественных новообразований (ЗНО) [Massetti GM et al, 2017]. На фоне депрессивных и тревожных состояний повышается, среди прочих видов рака, также и частота возникновения РПТК [Jia Y et al, 2017]. Между тем, РПТК и без того является одним из самых распространённых ЗНО во всём мире, как у мужчин, так и у женщин [Purim O et al, 2013]. Этот вид рака даже при применении самых современных методов лечения имеет относительно низкую 5-летнюю выживаемость (в западных странах она составляет всего $64 \%$, в России ещё ниже). Общая смертность от РПТК в мире превышает 500000 человек в год, что делает РПТК третьей по частоте причиной смертности среди всех $3 \mathrm{HO}$ [Purim O et al, 2013].

Известно и обратное явление: то, что практически любые ЗНО часто сопровождаются аффективными и тревожными нарушениями, причём нередко возникающими задолго до установления диагноза ЗНО (то есть не связанными с психологическими причинами, реакцией на болезнь, с ПЭ от лечения и др.). В некоторых случаях скрытое, ещё не обнаруженное, или находящееся в ранней и очень ранней стадии, ЗНО даже служит причиной резистентности к антидепрессантам (АД) [Быков ЮВ с соавт, 2013]. Между тем, именно при РПТК обнаруживается очень высокая частота коморбидных аффективных и тревожных нарушений [Purim O et al, 2013].

В свете всего вышесказанного, представляет большой интерес для клинической практики изучение статистической ассоциации и возмож- 
ных патофизиологических механизмов столь тесной двусторонней связи между аффективными и тревожными расстройствами, с одной стороны, и колопроктологическими заболеваниями, с другой стороны, а также возможностей одновременного лечения тех и других состояний.

При изучении имеющейся литературы по данному вопросу мы столкнулись с тем, что подобного систематического обзора, рассматривающего аффективные и тревожные расстройства в колопроктологии и их двустороннюю связь с колопроктологическими заболеваниями, на данный момент нет ни у российских, ни у западных авторов. Все имеющиеся на этот счёт исследования затрагивают лишь отдельные частные вопросы (например, вопрос о распространённости аффективных и тревожных расстройств при болезни Крона - БК, или при РПТК). Наш обзор является первым в данной области.

\section{Двусторонняя связь между различными колопроктологическими заболеваниями, и аффективными и тревожными расстройствами}

\section{Общие сведения}

Известно, что экзогенное введение воспалительных цитокинов (например, введение интерферона- $\alpha$ при лечении гепатита $\mathrm{C}$ или интерферона- $\beta$ при лечении рассеянного склероза) способно вызывать депрессивные и тревожные состояния. С другой стороны, известно, что антидепрессанты обладают противовоспалительным действием и снижают уровни воспалительных цитокинов в крови и ликворе [Udina $\mathrm{M}$ et al, 2012; McNutt MD et al, 2012]. Одним из важных медиаторов воспаления, наряду с прочими, является выделение из погибающих при воспалении клеток аденозина и аденозинтрифосфата (АТФ). В том числе это происходит и при воспалительных заболеваниях ЖКТ. Показано, что один из подтипов АТФ-рецепторов, так называемый P2X7R, играет важную роль в воспалительной активации микроглии в ЦНС, наблюдаемой при депрессивных состояниях [Evrensel A, Ceylan ME, 2015]. И наоборот, некоторые анилиновые красители, например, метиленовый синий и бриллиантовый синий $\mathrm{G}$, являются антагонистами $\mathrm{P} 2 \mathrm{X} 7 \mathrm{R}$, и проявляют противовоспалительное и антидепрессивное действие в экспериментах на животных [Ma M et al, 2014].

Известно, что депрессивные и тревожные состояния сопровождаются многообразными нейроэндокринными и иммунологическими нарушениями, и наоборот - эндокринные и иммунные дисфункции могут либо не- 
посредственно вызывать, либо способствовать развитию депрессивных и тревожных состояний или усугублять их [North CS et al, 2007]. Между тем, поскольку кишечник является не только органом пищеварения, но и важным лимфоидным и иммунным органом, а также важным органом внутренней секреции, притом тесно связанным с мозгом осью «мозг-кишечник-микробиота», то улучшение работы ЖКТ является необходимым условием для восстановления нормальной работы нарушенных при депрессиях и тревожных состояниях функций эндокринной и иммунной систем. Верно и обратное: расстройства ЖКТ, вызывая нейроэндокринные и иммунологические сдвиги, могут вызывать или усугублять депрессивные и тревожные состояния [Drossman DA et al, 1999].

Патофизиологические механизмы, обуславливающие тесную связь заболеваний ЖКТ с депрессивными и тревожными состояниями, многообразны. Среди них играют роль, в частности, висцеральная вегетативная нейропатия, генетические факторы, нарушения выработки ряда кишечных пептидов [De Winter BY et al, 2004], влияние расстройств ЖКТ на нарушения в биосинтезе и распаде ряда нейромедиаторов [O'Mahony $\mathrm{SM}$ et al, 2009], влияние на метаболизм гормонов и других гуморальных факторов, повышение секреции воспалительных цитокинов и снижение секреции противовоспалительных [Taché Y et al, 2009] и др.

Среди множества патофизиологических механизмов, играющих роль во взаимосвязи расстройств ЖКТ с депрессивными и тревожными состояниями, особое внимание привлекает роль вазоактивного интестинального пептида (VIP) [Mayer EA, 2011]. Этот пептид представляет из себя пептидный гормон, выделяемый кишечником и регулирующий моторику ЖКТ и его кровоснабжение, а также работу оси «мозг-кишечник». Он играет важнейшую роль в регуляции аппетита, процессов пищеварения, в модуляции функций лимфатической и иммунной системы, связанной с кишечником, а также в изменении общего физического и эмоционального состояния организма в ответ на приём пищи или напротив голодание [Van Oudenhove L et al, 2008].

Согласно другим исследованиям, изменения в секреции таких биологически активных веществ, как соматостатин и серотонин (5-гидрокситриптамин), эндорфины, также выделяемых кишечником, тоже могут быть вовлечены в патофизиологию как развития депрессивных и тревожных состояний, возникающих на фоне заболеваний ЖКТ, так и, напротив, возникновения заболеваний ЖКТ (например, СРК) на фоне имеющихся депрессивных и тревожных состояний [O’Mahony SM et al, 2010]. 
Недавние исследования также предоставили убедительные доказательства того, что депрессивные и тревожные расстройства негативно влияют на воспалительные процессы в кишечнике, вызывают нежелательное повышение проницаемости стенок кишечника, снижение барьерной функции слизистой, повышение секреции провоспалительных цитокинов и снижение противовоспалительных [Sajadinejad MS et al, 2012]. Существует даже теория, рассматривающая саму депрессию как следствие своеобразного низкоинтенсивного воспаления кишечника [Canli T, 2014].

Таким образом, у больных с колопроктологическими заболеваниями необходимо придавать особое значение своевременной диагностике и лечению депрессивных и тревожных состояний. И наоборот - следует своевременно диагностировать и лечить нарушения функции ЖКТ, такие, как хронические запоры или дисбактериоз кишечника, у депрессивных и тревожных больных. Необходимость этого часто недооценивается, что негативно влияет на качество жизни колопроктологических больных, ухудшает течение основного заболевания, снижает их работоспособность и функциональные возможности. Аналогичным образом, недооценка роли сопутствующих нарушений функции ЖКТ у депрессивных и тревожных больных также снижает их качество жизни, функциональные возможности и работоспособность, и способствует формированию резистентности депрессивных и тревожных состояний к психофармакотерапии (ПФТ) [Tsunoda A et al, 2005].

\section{Дисбактериоз кищечника, депрессия и тревога}

Достаточно давно известно, что кишечник является отнюдь не только органом пищеварения, но и одним из важнейших органов внутренней секреции. В частности, тонкий кишечник вырабатывает и секретирует в кровоток такие вещества, как вазоактивный интестинальный пептид (ВИП), секретин, холецистокинин, различные эндорфины и энкефалины. Все они, помимо локальных (паракринных) эффектов в кишечнике и воздействия на периферические ткани, проникают также и в ЦНС и оказывают влияние на её функции. В частности, секретин, холецистокинин и эндорфины играют роль в регуляции аппетита и насыщения. Толстый же кишечник, наряду с тонким кишечником и ЦНС, является одним из основных мест биосинтеза и выделения серотонина. Между тем, бытовавшее ранее представление о том, что серотонин из периферической крови не проходит в значимых количествах гематоэнцефалический барьер (ГЭБ) и, соответственно, не может оказывать какого-либо клинически 
значимого влияния на функционирование ЦНС, сегодня подверглось пересмотру. В настоящее время известно, что, хотя способность серотонина преодолевать ГЭБ относительно невелика, тем не менее она не равна нулю, и что содержание серотонина в периферической крови способно оказывать влияние на настроение и самочувствие, регуляцию аппетита, чувство тошноты и др. [Emmanuel A, Quigley EM, 2013].

В свете этого достаточно давно сформировалось представление о том, что ЦНС и кишечник связаны тесной двусторонней связью, и что как состояние ЦНС влияет на состояние кишечника, его моторику и секрецию, так и наоборот, состояние кишечника, секретируемые им в кровоток вещества и поступающие от него афферентные нервные импульсы, оказывает самое непосредственное влияние на функционирование ЦНС, на наше настроение и самочувствие. Этот комплекс представлений получил название представления об оси «мозг-кишечник» (brain-gut axis), по аналогии с такими осями взаимодействия, как ось «гипоталамус-гипофиз-надпочечники» (ГГН) и др. [Emmanuel A, Quigley EM, 2013]. Как клинические наблюдения, так и результаты экспериментов на животных убедительно показали, что ось «мозг-кишечник» формируется ещё во внутриутробном периоде (когда кишечник плода стерилен) и продолжает оказывать влияние на функционирование и развитие ЦНС на протяжении всей жизни индивидуума [Emmanuel A, Quigley EM, 2013; Borre YE et al, 2014].

Впоследствии было показано, что в упомянутой оси «мозг-кишечник» на самом деле имеется не два, а три звена, и что эта ось в действительности должна называться осью «мозг-кишечник-микробиота» (braingut-microbiota axis) [Emmanuel A, Quigley EM, 2013; Evrensel A, Ceylan $\mathrm{ME}, 2015]$. А именно, выяснилось, что состояние ЦНС непосредственно влияет как на функцию кишечника, так и на состав кишечной микрофлоры, и что многие психические заболевания, в частности, аффективные и тревожные состояния, сопровождаются вторичным нарушением бактериального баланса толстой кишки, дисбактериозом кишечника. Верно и обратное: первичные нарушения бактериального баланса толстой кишки, дисбактериоз кишечника, оказывают негативное влияние на настроение и самочувствие человека и могут служить одной из причин или усугубляющим фактором в развитии аффективных и тревожных расстройств [Emmanuel A, Quigley EM, 2013; Evrensel A, Ceylan ME, 2015].

При этом формируется патологический замкнутый круг, в котором депрессия и тревога вызывают или способствуют развитию дисбактериоза кишечника, а дисбактериоз кишечника ещё больше усугубляет проявления 
депрессии и тревоги. Этот замкнутый круг аналогичен другим описанным при депрессивных и тревожных состояниях порочным двусторонним взаимно усиливающим связям, возникающим, например, между депрессией и гиперактивностью оси ГГН, или между депрессией и социальной самоизоляцией [Emmanuel A, Quigley EM, 2013; Evrensel A, Ceylan ME, 2015].

Кроме того, показана роль нарушений баланса микрофлоры кишечника в патогенезе таких психических заболеваний, как шизофрения, расстройства аутистического спектра (РАС), синдром дефицита внимания с гиперактивностью или без таковой (СДВГ) [Evrensel A, Ceylan ME, 2015]. Дисбаланс кишечной микрофлоры играет также важную роль в патогенезе таких эндокринно-обменных нарушений, часто встречающихся коморбидно с психическими заболеваниями, как ожирение, сахарный диабет (СД), метаболический синдром (MC) [Evrensel A, Ceylan ME, 2015].

Механизмы такой связи пока окончательно не выяснены. Однако предполагается, что микробиом кишечника играет важную роль в поддержании нормального функционирования иммунной системы, и что микроорганизмы, населяющие толстый кишечник, находятся в тесном контакте как с эпителиальными клетками кишечника, так и с клетками иммунной системы, и оказывают влияние на секрецию ими цитокинов и других биологически активных веществ [Evrensel A, Ceylan ME, 2015]. B силу этого, вызванный нарушениями бактериального баланса кишечника воспалительный сдвиг в цитокиновом профиле может играть важную роль в патогенезе аутоиммунных заболеваний, а также вышеупомянутых эндокринно-обменных, сердечно-сосудистых и нервно-психических заболеваний [Evrensel A, Ceylan ME, 2015].

Немаловажно в данном контексте и то, что некоторые сапрофитные обитатели нашего кишечника, в частности, бифидобактерии, обладают способностью синтезировать серотонин, который затем захватывается энтерохромаффинными клетками толстой кишки, запасается в гранулах и затем медленно поступает в кровь, а также участие кишечной микрофлоры в биосинтезе некоторых важных для нормального функционирования ЦНС витаминов, таких, как витамины $\mathrm{B}_{12}$ и К. Биосинтез кишечной флорой этих витаминов не может заменить их поступления с пищей, однако покрывает часть потребностей организма хозяина (до трети по некоторым из них) [Emmanuel A, Quigley EM, 2013]. Соответственно, снижение биосинтеза серотонина и необходимых витаминов микрофлорой кишечника при развитии её дисбаланса также может играть роль в патогенезе депрессивных и тревожных состояний [Emmanuel A, Quigley EM, 2013]. 


\section{Хронические запоры, депрессия и тревога}

Как уже упоминалось нами выше, во введении, депрессивные и тревожные состояния настолько часто сопровождаются хроническими спастическими запорами, что этот симптом даже вошёл в классическую «триаду Протопопова» соматовегетативных признаков депрессии и тревоги [Gupta RK, 2009]. Предполагается, что основным патофизиологическим механизмом такой связи является повышенная при депрессивных и тревожных состояниях активность периферической симпато-адреналовой нервной системы, а также гиперкатехоламинемия, вызывающие спазмы прямой и толстой кишки и угнетение их перистальтики [Gupta RK, 2009].

Немалое значение в патогенезе хронических запоров при депрессивных и тревожных состояниях имеет также нередкое у этих больных снижение физической активности вплоть до адинамии, неправильное питание с нередким предпочтением сладкого, пониженным количеством в пище клетчатки, магния, растительного масла и других компонентов, препятствующих развитию запоров, а также курение, злоупотребление алкоголем и ПАВ, многие из которых также обладают угнетающим воздействием на перистальтику кишечника [Jia Y et al, 2017].

Способствует развитию запоров при депрессивных и тревожных состояниях также и наблюдаемый при них дисбактериоз, изменения бактериального баланса толстой кишки с преобладанием грамотрицательных бактерий и уменьшением количества «полезных» серотонин-синтезирующих штаммов бифидобактерий, а также лактобактерий и др. [Canli T, 2014]. Некоторыми авторами даже предлагается реконцептуализация депрессии и тревоги как своеобразного инфекционно-воспалительного или дисбиотического заболевания кишечника [Canli T, 2014].

Верно, однако, и обратное: при хронических запорах часто вторично развиваются депрессивные и тревожные состояния [Staller K et al, 2017; Hosseinzadeh ST et al, 2011]. Патофизиологию этого явления связывают с хронической каловой интоксикацией при запорах, с повышением проницаемости стенок прямой и толстой кишки при хронических запорах и попаданием антигенов и токсинов грамотрицательных бактерий в кровь, с развитием при хронических запорах вторичного дисбактериоза и умеренного (low-grade) воспаления слизистой прямой и толстой кишки, с возникающими при этом воспалительными сдвигами в цитокиновом профиле, повышением уровней оксидативного и нитрозативного стресса, со снижением секреции серотонина в толстом кишечнике и др. [Canli T, 2014]. 
Показано, что у пациентов с хроническими запорами наличие коморбидной депрессии и тревоги является более сильным предиктором абсентеизма (отсутствия на рабочем месте или на месте учёбы), и более сильным предиктором инвалидизации, нарушения трудоспособности и социальной адаптации, чем собственно тяжесть и выраженность симптомов хронического запора. Кроме того, коморбидная депрессия и тревога может усугублять тяжесть клинических проявлений хронического запоpa [Staller K et al, 2017]. И наоборот, доказано, что распространённость депрессивных и тревожных расстройств среди больных с хроническими запорами значительно выше, чем среди населения в целом [Hosseinzadeh ST et al, 2011].

\section{Геморрой, депрессия и тревога}

Важными факторами риска развития геморроя, как известно, являются хронические запоры или поносы, натуживание при дефекации, а также пониженная физическая активность, сидячий образ жизни, ожирение, СД, злоупотребление алкоголем, чрезмерно острой, пряной, перчёной или солёной пищей, курение, пониженное потребление с пищей клетчатки, растительного масла, пониженное потребление воды, старение организма [Kaidar-Person O et al, 2007; Lorenzo-Rivero S, 2009]. Все эти факторы риска с повышенной частотой встречаются у депрессивных и тревожных больных [Kaidar-Person O et al, 2007; Lorenzo-Rivero S, 2009]. В свете этого неудивительно, что депрессивные и тревожные больные с повышенной частотой страдают от геморроя [Fletcher BC et al, 2008; Elderon L, Whooley MA, 2013].

Существуют, однако, и специфические именно для депрессивных и тревожных состояний факторы риска, способствующие развитию геморроя у депрессивных и тревожных больных, даже вне связи с запорами, сидячим образом жизни и неправильным питанием. А именно, наблюдаемые при депрессивных и тревожных состояниях гиперкортизолемия, оксидативный стресс и повышенные уровни воспалительных цитокинов в крови способствуют ослаблению сосудистой стенки (в том числе стенок геморроидальных синусов), повышению её проницаемости, уменьшению содержания в ней коллагена и её более лёгкой травматизации при дефекации [Beck DE et al, 2011]. Повышенный при депрессивных и тревожных состояниях симпато-адреналовый тонус и гиперкатехоламинемия способствуют повышению тонуса анального сфинктера и повышению в нём давления, а также застою крови в геморроидальных синусах, что также 
способствует развитию геморроя [Beck DE et al, 2011]. Поэтому депрессия и тревога являются независимыми факторами риска риска развития геморроя, вне связи с наличием одновременно запоров, сидячим образом жизни, курением или другими упомянутыми выше факторами риска [Kaidar-Person O et al, 2007; Lorenzo-Rivero S, 2009].

С другой же стороны, геморрой сам по себе с повышенной частотой сопровождается развитием вторичных депрессивных и тревожных нарушений, или с усугублением уже имеющихся депрессии и тревоги [Fletcher BC et al, 2008; Elderon L, Whooley MA, 2013]. Предполагается, что в основе такой патофизиологической связи могут лежать такие факторы, как связанная с геморроем хроническая анальная боль (любые хронические болевые синдромы могут вызывать вторичные депрессивные и тревожные состояния), а также потери железа при геморроидальных кровотечениях (дефицит железа может вызывать депрессивные и тревожные нарушения или усугублять уже имеющиеся), или возникающие при геморрое вследствие страха больного перед болезненной дефекацией вторичные запоры (запоры, как мы уже упоминали выше, сами по себе ассоциируются с развитием вторичной депрессии и тревоги) [Fletcher ВC et al, 2008; Elderon L, Whooley MA, 2013].

\section{Анальные трещины, депрессия и тревога}

Важными факторами риска возникновения анальных трещин являются хронические запоры или поносы, натуживание при дефекации, пониженное потребление клетчатки и растительного масла с пищей, пониженное потребление воды, наличие у больного коморбидных ожирения, СД, гипотиреоза, воспалительных заболеваний кишечника (ВЗК), например, болезни Крона (БК) или неспецифического язвенного колита (НЯК), снижение физической активности, сидячий, малоподвижный образ жизни, спазм анального сфинктера, курение, сниженный кровоток в перианальной области (местный спазм сосудов), а также снижение местного иммунитета и регенеративных способностей тканей, которое препятствует спонтанному заживлению образовавшейся трещины [Mapel DW et al, 2014].

Между тем, многие из этих факторов риска (например, хронические запоры или поносы, снижение физической активности, сидячий малоподвижный образ жизни, курение, неправильное питание, ожирение, СД, гипотиреоз) с повышенной частотой встречаются у депрессивных и тревожных больных [Mapel DW et al, 2014]. Повышенная периферическая симпато-адреналовая активность и гиперкатехоламинемия, ча- 
сто наблюдаемые при депрессивных и тревожных состояниях, способствуют спазму анального сфинктера и нарушению местного кровотока, что также предрасполагает к развитию анальных трещин [Mapel DW et al, 2014].

Также часто наблюдаемые при депрессивных и тревожных состояниях гиперкортизолемия, иммунологические нарушения, относительная резистентность тканей депрессивных больных к инсулину и тиреоидным гормонам (даже при отсутствии явного СД2 или явного гипотиреоза), повышенный оксидативный и нитрозативный стресс, способствуют снижению местного иммунитета и репаративных способностей тканей, в том числе и в аноректальной области. Это способствует персистированию образовавшейся анальной трещины [Mapel DW et al, 2014]. В свете этого, неудивительно, что депрессивные и тревожные состояния, как таковые, оказались независимым фактором риска развития анальных трещин, вне зависимости от наличия или отсутствия других упомянутых факторов риска, таких, как хронические запоры, курение, гипотиреоз или ожирение, СД [Mapel DW et al, 2014].

По некоторым данным, изменённое эмоциональное состояние, в частности депрессия или тревога, играет важную роль в патогенезе анальных трещин. Это подчёркивает важность своевременного психологического и психиатрического обследования больных с анальными трещинами на предмет выявления у них коморбидной депрессии и/или тревоги [Cioli $\mathrm{VM}$ et al, 2015]. Показано также, что наличие коморбидной депрессии и/ или тревоги усугубляет течение анальных трещин, препятствует их заживлению, снижает эффективность их лечения [Arısoy Ö et al, 2017].

С другой же стороны, у больных с анальными трещинами с повышенной частотой встречаются депрессивные и тревожные состояния. Возможными патофизиологическими механизмами такой связи являются испытываемые больными с анальной трещиной хронические аноректальные боли (любой хронический болевой синдром может способствовать развитию депрессии или тревожного состояния), а также возникающие у таких больных, вследствие страха перед болезненностью дефекации, привычные хронические запоры (которые также сами по себе могут вызывать депрессивные и тревожные состояния), потери железа при кровоточащих трещинах (дефицит железа способен вызывать депрессивные и тревожные состояния) [Magni $\mathrm{G}$ et al, 1986]. Более половины больных с хроническими анальными трещинами страдают от коморбидной депрессии и/или коморбидного тревожного состояния [Magni $\mathrm{G}$ et al, 1986]. 


\section{Колоректальный и анальный рак, депрессия и тревога}

Как мы уже упоминали выше, во введении, любые ЗНО, в том числе скрытые, ещё не обнаруженные, или находящиеся в ранних и очень ранних стадиях, часто сопровождаются развитием депрессивных и тревожных нарушений, и даже могут быть причиной резистентности к АД [Быков ЮВ с соавт, 2013]. Справедливо это и для РПТК [Purim O et al, 2013].

Частота развития коморбидных депрессивных и тревожных состояний у больных с РПТК очень высока. Так, в одном исследовании было показано, что у женщин с раком анальной области, возникшим на фоне ВИЧ-инфекции, у $37 \%$ обнаруживалась коморбидная депрессия, у 54\% клинически значимая коморбидная тревожность [Battaglia TA et al, 2015].

У больных с любыми ЗНО, в том числе и с РПТК, наиболее распространёнными психическими расстройствами являются депрессивные и тревожные нарушения [Dunn J et al, 2006]. Распространённость депрессивных расстройств при РПТК, по данным нескольких исследований, составляет около 30-40\%, распространённость тревожных состояний ещё выше и достигает около 50\% [Tsunoda A et al, 2005; Teunissen S et al, 2007; Medeiros M et al, 2010]. Наличие коморбидной депрессии или тревоги снижает мотивацию к лечению РПТК, ухудшает прогноз заболевания, снижает общее качество жизни таких пациентов [Bottino SMB et al, 2009; Carmack CL et al, 2011; Wu SF et al, 2015].

Важной причиной развития депрессивных и тревожных нарушений при РПТК является то, что практикуемое при РПТК оперативное вмешательство нередко подразумевает наложение колостомы и пользование калоприёмником. Это приводит к инвалидизации и социальной изоляции больных и к негативным психологическим последствиям, в том числе к развитию депрессивных и тревожных нарушений, как психогенной реакции на колостомию и связанные с нею функциональные ограничения. Показано, что наибольшей выраженности эти депрессивные и тревожные нарушения достигают в среднем через 6 недель после оперативного вмешательства по поводу РПТК, и уменьшаются лишь через год и более, по мере психологической адаптации больного к наличию колостомы, а у части больных не уменьшаются никогда [Bosma E et al, 2016].

Предполагается, что патофизиологической основой подобной ассоциации ЗНО с возникающими на их фоне вторичными депрессивными и тревожными нарушениями могут служить также такие факторы, как секреция ЗНО различных токсинов и цитокинов, а иногда и гормонов (при гормонально-активных опухолях), воспалительные изменения в цитокиновом профиле, повышенное потребление растущим ЗНО таких важ- 
ных для нормального функционирования ЦНС и поддержания хорошего настроения и самочувствия питательных веществ и микроэлементов, как L-триптофан, цинк и др. [Быков ЮВ с соавт, 2013]. В случаях с уже установленным диагнозом ЗНО важное значение для развития депрессии или тревожного состояния имеют и такие факторы, как психологическая реакция пациента на болезнь и на её прогноз, на ПЭ от лечения, уровень собственно ПЭ от лечения, влияние болезни и лечения на общее качество жизни [Purim O et al, 2013].

С другой же стороны, как мы также уже упоминали выше, во введении, депрессивные и тревожные состояния сами по себе являются предрасполагающими факторами, факторами риска для развития ЗНО, в том числе РПТК [Massetti GM et al, 2017; Jia Y et al, 2017].

Предполагаемой патофизиологической основой для такой связи, общей для всех ЗНО, являются наблюдаемые при депрессивных и тревожных состояниях нарушения иммунитета (в том числе противоопухолевого), воспалительные сдвиги в цитокиновом профиле, повышение уровней оксидативного и нитрозативного стресса, митохондриальные нарушения, повышенная частота у депрессивных и тревожных больных развития ожирения и сахарного диабета 2-го типа (СД2), являющихся независимыми факторами риска для многих 3НО, а также повышенная у депрессивных и тревожных больных частота курения, злоупотребления алкоголем и психоактивными веществами (ПАВ) [Massetti GM et al, 2017; Jia Y et al, 2017].

Однако для связи депрессивных и тревожных состояний с повышением риска РПТК имеются также дополнительные специфические именно для этого вида ЗНО факторы риска, а именно, уже упоминавшаяся выше ассоциация депрессий и тревожных состояний с запорами (запоры независимый фактор риска РПТК), нередкая склонность депрессивных и тревожных больных к злоупотреблению сладкой и жирной пищей, в ущерб количеству в пище клетчатки и других растительных волокон (злоупотребление жирной пищей, а также пониженное содержание клетчатки в рационе - также независимые факторы риска РПТК), наблюдаемые при депрессиях и тревожных состояниях изменения бактериального баланса толстой кишки и умеренное хроническое воспаление её слизистой (воспаление слизистой ПК и ТК по любой причине, или явные ВЗК, такие, как БК, НЯК - также являются известными независимыми факторами риска РПТК) [Jia Y et al, 2017].

Повышенная частота депрессивных и тревожных состояний у пациентов с РПТК заставляет предполагать существование патофизиологиче- 
ского механизма, обуславливающего связь между развитием онкологических проблем и развитием аффективных и тревожных нарушений [Pyter $\mathrm{LM}$ et al, 2009]. В частности, у пациентов с различными ЗНО, в том числе с РПТК, наблюдается повышенный уровень провоспалительных цитокинов в крови, ликворе и ЦНС. Так, ещё в 1998 году было обнаружено, что при колоректальном раке наблюдается повышение уровня растворимого рецептора ИЛ-2-альфа (IL-2RA) в плазме крови, отражающее повышение уровня самого ИЛ-2, и что повышение уровней этих цитокинов коррелирует с тяжестью депрессии [Allen-Marsh TG et al, 1998]. Повышение уровней таких провоспалительных цитокинов, как ФНО- $\alpha$, ИЛ-1, ИЛ-2, ИЛ-6, способствует ускорению метаболизма L-триптофана по кинурениновому пути и повышению образования нейротоксичной кинуреновой кислоты, а также снижению образования серотонина и ускорению его распада при помощи моноаминоксидазы. Эти механизмы, вероятно, являются одной из патофизиологических основ, объясняющих высокую коморбидность между ЗНО, в особенности РПТК, и депрессивными и тревожными расстройствами [Fitzgerald P et al, 2008; Sertbas Y et al, 2012].

Таким образом, повышенные уровни воспалительных цитокинов являются факторами риска развития депрессивных симптомов у больных с РПТК. В свою очередь, методы терапии, способствующие снижению уровней воспалительных цитокинов, могут принести потенциальную терапевтическую пользу при депрессивных состояниях, возникающих на фоне РПТК [Archer JA et al, 2012].

Цитокиновая гипотеза депрессии, возникающей на фоне ЗНО, в частности, на фоне РПТК, основывается на предположении о том, что депрессивные и тревожные нарушения у больных с ЗНО, в том числе с РПТК, вызываются воспалительными цитокинами, которые продуцируются как непосредственно клетками самой опухоли, так и клетками повреждаемых и сдавливаемых опухолью окружающих тканей, и борющимися с опухолью иммунокомпетентными клетками. В свою очередь, эти воспалительные цитокины оказывают неблагоприятное воздействие на нейроэндокринную систему, на работу оси «гипоталамус-гипофиз-надпочечники», на метаболизм L-триптофана и серотонина и др. Всё это в сумме и приводит к развитию депрессивных и тревожных нарушений у больных с 3НО, в частности с РПТК [Illman J et al, 2005; Rich T et al, 2005; Wedding U et al, 2008; Seruga B et al, 2008].

Цитокиновая гипотеза депрессии при ЗНО подтверждается, в частности, исследованиями, показывающими наличие корреляции между 
уровнями в плазме провоспалительных цитокинов, и выраженностью тревожных и депрессивных симптомов, например, у пациенток с раком яичников [Späth-Schwalbe E, et al, 1998; Musselman DL et al, 2001]. Исследования показывают, что у пациентов с РПТК наблюдается повышенный уровень в плазме таких провоспалительных цитокинов, как ИЛ-1, ИЛ-2, ИЛ-6, ИЛ-8, ФНО- $\alpha$, и одновременно снижение содержания в плазме таких противовоспалительных цитокинов, как ИЛ-10. При этом обнаруживается статистически достоверная положительная корреляция между показателями депрессии и тревоги по Госпитальной шкале тревоги и депрессии (HADS) и уровнями воспалительных цитокинов ИЛ-1, ИЛ-2, ИЛ-6, ИЛ-8, ФНО- $\alpha$, и статистически достоверная отрицательная корреляция между показателями депрессии и тревоги по шкале HADS, и уровнем противовоспалительного цитокина ИЛ-10. Эти данные указывают на то, что повышение уровней циркулирующих провоспалительных цитокинов и снижение уровней противовоспалительных цитокинов играет важную роль в патофизиологических механизмах развития депрессии и тревоги у больных с РПТК [Oliveira Miranda D et al, 2014].

Во множестве исследований показано, что РПТК, так же как и депрессивные и тревожные состояния, сопровождается снижением секреции фактора роста нервных клеток (BDNF) и повышением активности TrkB сигнального пути [de Farias CB et al, 2012; Tanaka K et al, 2014]. Снижение секреции BDNF при РПTК, понижая нейрогенез и усиливая апоптоз нервных клеток, способствует развитию коморбидных депрессивных и тревожных состояний. С другой же стороны, активация TrkB сигнального пути при депрессивных и тревожных состояниях способствует усилению таких неблагоприятных биологических процессов у больных с РПТК, как опухолевая пролиферация, инвазия и метастазирование (миграция), эпителиально-мезенхимальный переход, а также способствует повышению устойчивости опухолевых клеток к апоптозу [Akil H et al, 2016]. Вышеописанный механизм также является одним из важных патогенетических звеньев, связывающих депрессивные и тревожные состояния и РПТК в обе стороны, и способствующих ухудшению течения обоих заболеваний [de Farias CB et al, 2012; Tanaka K et al, 2014; Akil H et al, 2016].

\section{Воспалительные заболевания кищечника, депрессия и тревога}

Как мы уже упоминали выше, депрессивные и тревожные состояния, как таковые, сами по себе сопровождаются патологическим повышением проницаемости стенок кишечника для грамотрицательных бактерий, 
повышенным проникновением их антигенов и токсинов в кровь, нарушением бактериального баланса толстой кишки с избыточным размножением грамотрицательных бактерий, снижением количества «полезных» серотонин-синтезирующих бифидобактерий, а также лактобактерий, и хроническим низкоинтенсивным (low-grade) воспалением стенок кишечника [Canli T, 2014]. Некоторые авторы считают эти факторы настолько значимыми в патогенезе депрессивных и тревожных расстройств, что даже предлагают реконцептуализацию депрессивных и тревожных расстройств как своеобразных инфекционно-воспалительных или дисбиотических заболеваний кишечника [Canli T, 2014].

С другой же стороны, в колопроктологии известны первичные идиопатические воспалительные заболевания кишечника (ВЗК), а именно - болезнь Крона (БК) и неспецифический язвенный колит (НЯК). Их этиология и патогенез на данный момент остаётся окончательно не выясненными. Тем не менее, на сегодняшний день ВЗК принято интерпретировать как аутоиммунные или ревматологические заболевания. В этиологии и патогенезе ВЗК, как установлено на данный момент, наряду с иммунологическими, играют роль также генетические и экологические факторы (в частности, генетическая предрасположенность к аутоиммунным заболеваниям, както наличие антигена HLA-B27, а также характер питания, бактериальный биоценоз в ТК и др.) [Nowakowski J et al, 2016].

Статистически показано, что ВЗК могут провоцировать развитие коморбидной депрессии и тревоги и наоборот [Kurina LM et al 2001]. B частности, показано, что у приблизительно 60\% больных с ВЗК наблюдается сопутствующая депрессия и/или тревога [Addolorato $\mathrm{G}$ et al, 1997]. Особенно высокий риск развития депрессивного или тревожного состояния наблюдается в течение первого года после установления диагноза ВЗК, что связывают, среди прочих факторов, с психологической реакцией на болезнь и на её возможный тяжёлый прогноз [Kurina LM et al, 2001].

Показано, что наличие коморбидной депрессии или тревоги отрицательно влияет на течение ВЗК, способствует его более активному и агрессивному течению, более частым обострениям заболевания, более частому возникновению осложнений ВЗК, усугубляет симптомы ВЗК, ухудшает общий прогноз заболевания и прогноз в отношении сохранения трудоспособности [Graff LA et al, 2009]. Кроме того, наличие коморбидной депрессии или тревоги также снижает эффективность терапии ВЗК, клинический ответ на терапию, и повышает вероятность того, что больному с ВЗК потребуются хирургическое вмешательство (частичная резекция 
кишечника) или дорогостоящие биологические методы лечения [Persoons $\mathrm{P}$ et al, 2005]. Важно и то, что депрессия снижает мотивацию больных с ВЗК к соблюдению режима лечения и диеты, к регулярному приёму предписанных лекарств, и это тоже способствует ухудшению прогноза заболевания, повышению вероятности обострений и осложнений, потери трудоспособности [Persoons P et al, 2005].

Многочисленные данные как строгих клинических исследований и эмпирических наблюдений, так и опытов на животных с экспериментальными моделями ВЗК, систематически показывают, что проявления ВЗК значительно усиливаются при наличии сопутствующих депрессивных или тревожных нарушений [Ghia JE et al, 2008]. В частности, исследования, проведённые у больных с НЯК, показывают, что депрессия и тревога являются независимыми факторами риска развития рецидивов и осложнений при этом заболевании [Mittermaier C et al, 2004].

Предполагается, что в основе патофизиологических механизмов, обуславливающих столь тесную двустороннюю связь депрессивных и тревожных состояний с ВЗК, лежат такие явления, как иммунологические нарушения, в частности, гиперсекреция воспалительных цитокинов, окислительный и нитрозативный стресс, дисфункция блуждающего нерва, нарушения в работе оси «мозг-кишечник-микробиота» (brain-gut-microbiota axis), в частности, уже упоминавшийся дисбактериоз кишечника [Nowakowski J et al, 2016]. Все эти явления в определённой степени характерны как для депрессивных и тревожных состояний самих по себе, так и для ВЗК самих по себе, а при их сочетании взаимно усиливают друг друга [Nowakowski J et al, 2016].

Важную роль в патогенезе депрессивных и тревожных состояний при ВЗК играет также нередко возникающая при ВЗК мальабсорбция (нарушение всасывания и усвоения) ряда важных для нормального функционирования ЦНС и для поддержания хорошего настроения и самочувствия витаминов, аминокислот и микронутриентов, таких, как витамин $\mathrm{B}_{12}$, фолиевая кислота, железо, медь, цинк, магний и др. [Nowakowski J et al, 2016].

Существенна в развитии этих нарушений и роль мальдигестии (нарушения питания, возникающего как вследствие сопутствующей относительной ферментной недостаточности, так и вследствие сознательного ограничения больным диеты и количества потребляемой пищи, из страха перед обострением заболевания) [Nowakowski J et al, 2016].

При анализе большой когорты больных с ВЗК обнаружена статистически достоверная связь между наличием симптомов коморбидной депрессии и тревоги, и вероятностью клинического рецидива или ослож- 
нений ВЗК, а также между наличием симптомов коморбидной депрессии или тревоги, и худшим ответом на терапию и худшим прогнозом заболевания и восстановления трудоспособности. Поэтому все пациенты с ВЗК должны быть обследованы на предмет наличия у них коморбидных депрессивных и тревожных расстройств [Mikocka-Walus A et al, 2016].

Выявление и лечение коморбидной депрессии и тревоги при ВЗК не только улучшает общее качество жизни таких больных, но и улучшает прогноз лечения собственно ВЗК, повышает мотивацию больных к лечению, уменьшает количество рецидивов и обострений заболевания, риск его осложнений, способствует сохранению или восстановлению трудоспособности больных с ВЗК [Abautret-Daly Á et al, 2017].

\section{Целиакия, депрессия и тревога}

Целиакия - это хроническое аутоиммунное, воспалительное заболевание кишечника, которое, в отличие от описанных в предыдущем разделе идиопатических ВЗК, таких, как БК и НЯК, возникает вследствие специфической токсико-аллергической реакции кишечника чувствительных к глютену (белку пшеницы и некоторых других зерновых) больных на поступление глютена с пищей [Kukla U et al, 2015].

Целиакия имеет множество внекишечных проявлений, в том числе проявлений со стороны ЦНС или психики. В частности, она ассоциируется с такими разнообразными психическими заболеваниями, как депрессивные и тревожные расстройства, РАС, СДВГ, и даже расстройства шизофренического спектра (РШC) [Kukla U et al, 2015].

Основным методом лечения целиакии является соблюдение больным строгой безглютеновой диеты [Kukla U et al, 2015].

Интересно отметить, что такое многообразие вызываемых целиакией психических нарушений даже послужило основанием для того, чтобы некоторые деятели антипсихиатрического движения, отрицающие само существование психических заболеваний как таковых, в союзе с «альтернативными психиатрами» (также называющими себя «ортомолекулярными психиатрами») и другими сторонниками альтернативной медицины, подняли целиакию «на щит», и объявили её единственной настоящей причиной всех психических заболеваний. Соответственно, они попытались лечить все упомянутые психические заболевания безглютеновой диетой [Kukla U et al, 2015].

При этом, хотя у большинства психически больных, без предварительно установленного диагноза целиакии, никакого эффекта от безглю- 
теновой диеты не отмечалось, у некоторых таких больных при введении безглютеновой диеты действительно отмечено улучшение психического состояния, а при возвращении глютена в пищу снова наступало ухудшение. Это даёт основания предполагать, что, по крайней мере в некоторых редких случаях, причиной психических нарушений, и в том числе депрессивных и тревожных расстройств, действительно может служить латентная, слабо выраженная целиакия, без ярких кишечных проявлений [Kukla U et al, 2015].

\section{Синдром раздражённого кищечника, депрессия и тревога}

Синдром раздражённого кишечника (СРК) - это классическое психосоматическое заболевание, в патогенезе которого значительную роль играют коморбидные депрессивные и тревожные нарушения, хронический психоэмоциональный стресс, а также повышенная висцеральная болевая чувствительность, сенситизация спинальных и центральных ноцицептивных структур, хроническое низкоинтенсивное (low-grade) воспаление слизистой ТК и её эозинофильная инфильтрация, нарушения бактериального баланса ТК (дисбактериоз) [Emmanuel A, Quigley EM, 2013]. Наблюдается также и обратная корреляция - при СРК с повышенной частотой выявляются коморбидные депрессивные и тревожные нарушения [Emmanuel A, Quigley EM, 2013].

\section{Хроническая идиопатическая анальная боль}

\section{или зуд, депрессия и тревога}

При хронической идиопатической анальной боли и хроническом идиопатическом анальном зуде часто наблюдаются коморбидные депрессивные и тревожные расстройства [Renzi C, Pescatori M, 2000]. Наблюдается также и обратная корреляция - при депрессивных и тревожных состояниях хроническая идиопатическая анальная боль или хронический идиопатический анальный зуд встречаются с повышенной частотой [Renzi C, Pescatori M, 2000].

\section{Хроническое недержание кала, депрессия и тревога}

У больных с хроническим недержанием кала с повышенной частотой наблюдаются коморбидные депрессивные и тревожные расстройства [Grano C et al, 2014]. Особенно часто коморбидные депрессивные и тревожные расстройства в этой категории больных наблюдаются среди мужчин [Grano C et al, 2014]. 


\section{Анизм, депрессия и тревога}

При анизме (хроническом спазме заднего прохода, нередко психогенном и нередко сопровождаемом болезненностью), часто наблюдаются коморбидные депрессивные и тревожные расстройства, а также такие функциональные и также нередко имеющие психогенную природу коморбидные расстройства, как психогенная дисфагия, ощущение «комка в горле», аэрофагия, функциональная диспепсия, СРК, функциональные боли в животе, функциональные урологические и сексуальные нарушения и др. [Bouchoucha $\mathrm{M}$ et al, 2004]. Анизм также часто сопровождается вторичными запорами, каломазанием или недержанием кала, дисхезией, метеоризмом, что также оказывает негативное влияние на психологическое состояние больных с анизмом и на их способность социализироваться в обществе [Bouchoucha $\mathrm{M}$ et al, 2004]. Вероятно и обратное явление, когда анизм возникает как вторичная психогенная реакция на наличие метеоризма, запоров или проблем с удержанием кала, болезненностью дефекации [Bouchoucha $\mathrm{M}$ et al, 2004].

С другой же стороны, показано, что сами по себе депрессивные и тревожные состояния, наряду с вызываемой ими тенденцией к напряжению скелетных мышц и к повышенному их тонусу, сопровождаются также повышением давления в заднем проходе, тенденцией к спазму анального сфинктера, к развитию анизма [Del Popolo F et al, 2014]. Обучение же расслаблению ануса и общей релаксации мышц при помощи аппаратуры биологической обратной связи (БОС) способствует не только устранению анизма (спазма анального сфинктера), но и нормализации или улучшению психического состояния, уменьшению депрессии и тревоги [Del Popolo F et al, 2014].

\section{Колопроктологические побочные эффекты психиатрического лечения}

Многие психотропные препараты, прежде всего обладающие выраженной М-холиноблокирующей или $\mathrm{H}_{1}$-гистаминоблокирующей активностью (например, АД из группы трициклических антидепрессантов - ТЦА, низкопотентные антипсихотики - АП типа хлорпромазина, клозапина), а также седативные препараты и препараты, повышающие периферическую норадренергическую активность (например, АД группы селективных ингибиторов обратного захвата серотонина и норадреналина - СИОЗСиН, или психостимуляторы - ПС), способны вызывать хронические запоры [Stahl SM, 2013]. 
Между тем, как уже упоминалось нами выше, хронические запоры, в свою очередь, способны вызвать появление таких вторичных колопроктологических осложнений, как геморрой, анальные трещины, а также способствовать усугублению депрессии или развитию её резистентности к АД. Кроме того, хронические запоры, вызываемые психотропными препаратами, служат частой причиной отказа от лечения или снижения приверженности к нему, периодических пропусков приёма лекарств. Поэтому важность своевременного выявления и коррекции этого ПЭ для повышения приверженности больного к психотропному лечению, для улучшения результатов лечения депрессии и общего качества жизни больного, для преодоления резистентности нельзя недооценивать [Stahl SM, 2013].

Многомесячные или многолетние хронические запоры, как уже упоминалось нами выше, также служат важным фактором риска развития РПТК.

С другой же стороны, ряд психотропных препаратов, повышающих серотонинергическую активность в кишечнике, например, препараты лития, АД из группы селективных ингибиторов обратного захвата серотонина СИОЗС, вальпроаты - склонны вызывать, напротив, поносы. Как правило, этот ПЭ отмечается только в начале терапии, и постепенно проходит по мере адаптации к тому или иному препарату. Однако в некоторых случаях понос, вызванный тем или иным психотропным препаратом (например, литием) не проходит по мере адаптации и не исчезает даже при длительном многомесячном приёме причинного препарата [Stahl SM, 2013].

Между тем, как уже упоминалось нами выше, хроническая диарея также может служить причиной развития таких вторичных колопроктологических осложнений, как геморрой, анальные трещины, дисбактериоз кишечника. Она также может служить причиной снижения приверженности больного к терапии данным препаратом, пропусков лечения или отказа от дальнейшего приёма препарата. Поэтому своевременное выявление и коррекция этого ПЭ также имеет важное значение как для профилактики упомянутых осложнений, так и для повышения приверженности больного к ПФТ и улучшения общего качества его жизни [Stahl SM, 2013].

\section{Психиатрические побочные эффекты колопроктологического лечения}

\section{Химиотерапия, радиотерапия и хирургические вмешательства}

Как уже упоминалось нами выше, химиотерапия, радиотерапия и хирургическое вмешательство, применяемые в качестве основных методов 
лечения РПТК, в качестве одного из частых ПЭ нередко вызывают такие психиатрические осложнения, как развитие депрессивных и тревожных состояний [Thong MS et al, 2011; Bentzen AG et al, 2013].

Патофизиологические механизмы депрессогенного влияния этих вмешательств многообразны и включают в себя как наличие у них тяжёлых соматических ПЭ (алопеция, иммуносупрессия, миелосупрессия и др. при применении химиотерапии, лучевой колит или проктит при радиотерапии и др.) и связанное с ними общее ухудшение качества жизни пациента, так и такие, например, факторы, как психогенная реакция пациента на наложение колостомы, и связанное с этими вмешательствами нарушение бактериального баланса кишечника и работы оси «мозг-кишечник-микробиота», и нередко развивающиеся вследствие тошноты, рвоты и анорексии дефициты питательных веществ, витаминов и микроэлементов, важных для нормального функционирования ЦНС, и непосредственное нейротоксическое влияние химиопрепаратов [Быков ЮВ с соавт., 2013].

\section{Глюкокортикоиды}

Депрессогенное и анксиогенное воздействие экзогенных глюкокортикоидов, так же как и их способность вызывать множество других нейропсихиатрических ПЭ, например, бессонницу, галлюцинации, стероидные мании и стероидные психозы, известно давно [Быков ЮВ с соавт, 2013]. Более того, известно, что наблюдаемая при депрессивных и тревожных состояниях, психозах гиперкортизолемия и гиперактивность оси ГГН играют важную роль в патогенезе этих состояний [Быков ЮВ с соавт, 2013].

\section{Аминосалицилать}

Описано несколько клинических случаев депрессии, связанной с применением сульфасалазина или салазопиридазина [Scherer J, 1988; Rebrov VG, Lukomskiı̌ MI, 1989]. Патофизиологические механизмы возможного депрессогенного влияния аминосалицилатов пока не выяснены.

\section{Хлорохин и гидроксихлорохин}

Способность хлорохина и гидроксихлорохина, нередко применяемых в качестве противовоспалительных агентов при ВЗК, вызывать различные нейропсихиатрические ПЭ, варьирующие в диапазоне от провокации депрессивных и тревожных состояний, панических атак, до галлюцинаций и даже психозов, фармакогенных маниакальных состояний, известна давно [de Oliveira Ribeiro NP et al, 2013]. 
Так, в частности, недавно описан случай провокации хлорохином фаз обоего знака (депрессивных или маниакальных) у больного с биполярным аффективным расстройством (БАР), коморбидным с БК и системной красной волчанкой (СКВ) при каждой попытке назначения хлорохина [Bogaczewicz J et al, 2014]. Известна также способность хлорохина или гидроксихлорохина обострять суицидальные тенденции или вызывать спутанность сознания и нарушения памяти, приводящие к случайным опасным его передозировкам [Good MI, Shader RI, 1982].

\section{Иммуносупрессоры цитостатического ряда}

Некоторые препараты цитостатического ряда, в частности, метотрексат, азатиоприн, меркаптопурин, тиогуанин, реже циклофосфамид, в малых дозах используются в качестве иммуносупрессоров, противоревматических и противовоспалительных средств при различных незлокачественных заболеваниях: аутоиммунных, ревматических и др., в том числе и при ВЗК. Некоторые из них, обладающие относительно избирательным цитостатическим действием на активированные лимфоциты, такие, как лефлуномид, микофенолат мофетил, используются исключительно в роли иммуносупрессоров при этих заболеваниях.

Показано, что все эти препараты могут давать нейропсихиатрические ПЭ, в частности, депрессивные и тревожные состояния [de Oliveira Ribeiro NP et al, 2013]. Описан случай провокации маниакального состояния метотрексатом [Hariram J, Jegan Y, 2013].

Патофизиологические механизмы депрессогенного влияния иммуносупрессоров цитостатического ряда могут включать в себя прямое нейротоксическое действие (угнетение нейрогенеза и способствование апоптозу нервных клеток), и, в случае метотрексата, также угнетающее влияние на активность ферментов фолатного цикла, что приводит к повышению уровня гомоцистеина, нарушению синтеза тетрагидробиоптерина (BH4) и, как следствие, нарушениям в биосинтезе моноаминов, кофактором для некоторых стадий которого ВН4 является [Hariram J, Jegan Y, 2013].

\section{Антицитокиновые препараты}

Несмотря на то, что большинство исследований указывают на наличие антидепрессивных и противотревожных свойств у антагонистов ФНО- $\alpha$, таких, как инфликсимаб, этанерцепт, и у антагонистов ИЛ-1 (Анакинра), некоторые данные указывают и на то, что эти препараты в ряде случаев сами могут провоцировать депрессивные и тревожные состояния, психо- 
зы и даже приводить к суициду [Eshuis EJ et al, 2010]. Эту возможность всегда следует иметь в виду клиницисту, применяющему эти современные препараты.

\section{Применение психотропных лекарств как терапевтических агентов при колопроктологических заболеваниях}

\section{Антидепрессанты}

Известно, что АД обладают, кроме прочих своих эффектов, также иммуномодулирующей и противовоспалительной активностью, а также способностью повышать уровни BDNF, NGF, VEGF и других факторов роста нервных и эпителиальных клеток [Tamaji A et al, 2012]. Это может оказать положительное действие на течение ВЗК, уменьшить выраженность воспаления слизистой ТК, иммунологических сдвигов, способствовать восстановлению целостности слизистой ТК, улучшению её регенерации под влиянием упомянутых факторов роста [Tamaji A et al, 2012]. В то же время известно, что при депрессивных и тревожных состояниях, так же как и при воспалительных и аутоиммунных заболеваниях, уровни BDNF и других факторов роста и активность TrkB сигнального пути снижается, а уровни про-апоптотических белков, таких, как сортилин и $\mathrm{p} 75 \mathrm{~N}$, повышается [Zhou L et al, 2013].

Противовоспалительное действие было показано в экспериментах в разных моделях воспаления (в том числе в моделях ВЗК) и в клинике для таких разных АД, как флуоксетин [Abdel-Salam OM et al, 2004], амитриптилин [Sadeghi H et al, 2011], мапротилин [Hajhashemi V et al, 2010], венлафаксин [Aricioğlu $\mathrm{F}$ et al, 2005], дезипрамин [Greenbaum DS et al, 1987]. Для некоторых из них, в частности, венлафаксина, дезипрамина, амитриптилина, показано также выраженное анальгетическое (антиноцицептивное) действие, связанное с модуляцией активности обеих основных моноаминергических систем - серотонинергической и норадренергической [Greenbaum DS et al, 1987; Aricioğlu F et al, 2005; Sadeghi H et al, 2011].

Как показывают многочисленные исследования, лечение депрессивных и тревожных состояний у колопроктологических больных с ВЗК при помощи АД оказывает положительное влияние не только на их психическое состояние, на уровни тревоги и депрессии, на общее качество их жизни, но и на их соматическое состояние и активность собственно ВЗК, выраженность воспаления, частоту рецидивов и обострений ВЗК [Deter 
HC et al, 2008; Filipovic BR, Filipovic BF, et al, 2014; Taché Y, Bernstein $\mathrm{CN}, 2009]$. Поэтому своевременное выявление и лечение с помощью АД коморбидных депрессивных и тревожных состояний при ВЗК очень важно и должно проводиться обязательно [Deter HC et al, 2008; Filipovic BR, Filipovic BF, et al, 2014; Taché Y, Bernstein CN, 2009].

Так, в одном РКИ, в котором участвовали 80 пациентов с БК, показано, что лечение коморбидной депрессии и тревоги при помощи АД и связанное с этим снижение уровней депрессии, тревоги и стресса статистически достоверно $(\mathrm{p}<0,05)$ значительно снижает индекс активности БК и число обострений в течение последующего года [Milne B et al, 1986].

Важно, что некоторые классы АД, влияющие одновременно на серотонинергическую и норадренергическую системы нейропередачи, а именно ТЦА и СИОЗСиН, обладают также выраженной анальгетической активностью [Stahl SM, 2013]. Это, наряду с их противовоспалительными свойствами, делает их предпочтительными при лечении таких колопроктологических заболеваний, как ВЗК и СРК, часто протекающие с болевым синдромом [Jain R, Jain S, 2011].

Анальгетические свойства ТЦА и СИОЗСиН и их способность тормозить перистальтику кишечника за счёт антихолинергического или норадренергического действия могут эффективно использоваться у пациентов с тенезмами, с СРК с преобладанием болей или поносов (причём могут быть эффективны малые дозы, например 10-25-50 мг/сут амитриптилина) [Livovsky DM et al, 2015].

И наоборот, у пациентов с СРК с преобладанием запоров могут быть эффективно использованы СИОЗС, а также такие обладающие свойствами прокинетиков психотропные препараты, как сульпирид (эглонил) [Emmanuel A, Quigley EM, 2013].

Анальгетические свойства ТЦА или СИОЗСиН могут также быть с успехом использованы при идиопатической аноректальной боли и связанных с нею трудностях с дефекацией [Atkin GK et al, 2011]. Показано также, что ТЦА или СИОЗСиН способны уменьшить клинические проявления синдрома недержания кала [Scarlett Y, 2004].

Резюмируя, многие психотропные препараты, в частности АД, имеют ряд свойств, полезных в колопроктологической практике, например, анальгетические, противовоспалительные, иммуномодулирующие, спазмолитические, прокинетические (сульпирид) или, напротив, тормозящие перистальтику кишечника (ТЦА, СИОЗСиН), и заслуживают более широкого применения в колопроктологии. 


\section{Применение колопроктологических лекарств и методов лечения при депрессивных и тревожных состояниях}

\section{Антицитокиновые препараты}

Как мы уже неоднократно указывали выше, депрессивные и тревожные состояния часто сопровождаются неблагоприятными воспалительными сдвигами в цитокиновом профиле, в частности, повышением уровней таких воспалительных цитокинов, как ФНО- $\alpha$, ИЛ-1, ИЛ-2, ИЛ-6, ИЛ-8, ИЛ-17А. Более того, было показано, что хроническое воспаление и воспалительные сдвиги в цитокиновом профиле играют важную роль в патогенезе депрессивных и тревожных состояний, в частности, через влияние упомянутых цитокинов на активность индоламин-диоксигеназы и метаболизм серотонина, на активность оси «гипоталамус-гипофиз-надпочечники», на уровень окислительного стресса и др. [Fitzgerald $\mathrm{P}$ et al, 2008; Sertbas Y et al, 2012].

В свете этого, неудивительно, что антагонисты упомянутых цитокинов, в частности, применяемые в колопроктологии для лечения ВЗК антагонисты ФНО- $\alpha$, такие, как этанерцепт и инфликсимаб, привлекли внимание специалистов, занимающихся лечением депрессивных и тревожных состояний, в качестве перспективных терапевтических агентов. Первоначально было обращено внимание на улучшение психического состояния больных, получавших эти препараты для лечения аутоиммунных и ревматических заболеваний [Kappelmann $\mathrm{N}$ et al, 2016]. Затем было показано, что эти препараты способны улучшать настроение и самочувствие депрессивных больных и повышать эффективность АД и в отсутствие коморбидных аутоиммунных или ревматических заболеваний [Kappelmann N et al, 2016].

Показано наличие антидепрессивной активности и у антагонистов ИЛ-1 (Анакинра) [Kappelmann N et al, 2016], антагонистов ИЛ-6, ИЛ-17А, также применяемых в колопроктологии при ВЗК [Griffiths CEM et al, 2017].

\section{Аминосалицилаты}

Сульфасалазин, известный противовоспалительный агент, широко применяемый при ВЗК (в частности, БК, НЯК), а также при СРК и при различных ревматических и аутоиммунных заболеваниях, недавно привлёк внимание исследователей в новом качестве. А именно, выяснилось, что сульфасалазин (именно как целое, а не выделяющийся при его метаболизме 5-аминосалицилат) является блокатором так называемого «системного антипортера», аминокислотного насоса, меняющего глутамат 
на ГАМК, в различных клетках организма, в том числе в клетках нейроглии [Nashed MG et al, 2017]. Одновременно он является антагонистом NMDA-рецепторов, и, благодаря этим свойствам, проявляет нейропротективную и антидепрессивную активность в экспериментальной модели депрессии, вызванной наличием ЗНО, у животных, поскольку раковые клетки имеют повышенную активность системного антипортера и выделяют в кровь большое количество глутамата [Nashed MG et al, 2017].

Авторы исследования предположили, что сульфасалазин может быть перспективным терапевтическим агентом в комплексном лечении депрессий, возникающих на фоне ЗНО (в том числе РТПК), - депрессий, часто плохо поддающихся терапии АД, и призвали к его изучению в этом качестве у человека [Nashed MG et al, 2017].

\section{Кичечные антибиотики, пребиотики и пробиотики}

Как мы уже упоминали выше, депрессивные и тревожные состояния нередко сопровождаются развитием вторичного дисбактериоза кишечника и связанного с ним низкоинтенсивного хронического воспаления слизистой толстой кишки, повышением её проницаемости для антигенов и токсинов грамотрицательных бактерий, нарушениями моторики кишечника (поносами или запорами) [Evrensel A, Ceylan ME, 2015]. И наоборот, первичный дисбактериоз кишечника (например, вызванный применением АБ широкого спектра действия, химиотерапией, ионизирующим облучением, хроническими запорами, поносами, наличием ВЗК и др.), часто сопровождается развитием вторичных депрессивных и тревожных состояний [Evrensel A, Ceylan ME, 2015]. Некоторые теории даже рассматривают сами депрессивные и тревожные состояния как своеобразные низкоинтенсивные инфекционно-воспалительные заболевания кишечника или как следствие дисбиотического состояния кишечника, то есть придают этим нарушениям центральное значение в патогенезе депрессивных и тревожных состояний [Canli T, 2014].

В свете этих данных, неудивительно, что и учёными-исследователями, и клиницистами-практиками были предприняты попытки применения как специфических неабсорбируемых или имеющих узконаправленный спектр кишечных АБ (типа перорального неомицина, рифаксимина, метронидазола, ванкомицина), так и пребиотиков и пробиотиков с целью коррекции как дисбиотических нарушений, так и собственно депрессивных и тревожных проявлений, вне зависимости от того, какое из нарушений является первичным, а какое - вторичным. В доклинических исследованиях на 
грызунах было показано, что некоторые кишечные АБ, пребиотики и пробиотики действительно могут оказывать антидепрессивное и противотревожное действие в экспериментальных моделях депрессии и тревоги. При этом полученные данные позволили предположить, что антидепрессивное и противотревожное действие кишечных АБ, пребиотиков и пробиотиков, вероятнее всего, реализуется через их влияние на цитокиновый профиль крови, через балансировку активности клеток иммунной системы и, опосредованно через неё, на состояние нейроэндокринной системы (в частности, системы ГГН, активируемой воспалительными цитокинами и подавляемой цитокинами противовоспалительными) и на обмен нейромедиаторов, в частности, серотонина (через влияние цитокинов на активность индоламин-диоксигеназы) [Evrensel A, Ceylan ME, 2015].

В дальнейшем антидепрессивная и противотревожная активность кишечных АБ, пребиотиков и пробиотиков была также подтверждена клинически, и сегодня они рассматриваются как перспективные терапевтические агенты в комплексном лечении депрессивных и тревожных состояний, в том числе при резистентности к традиционным АД [Bruce-Keller AJ et al, 2017].

Известно, что АД, среди прочих своих эффектов, таких, как влияние на обмен нейромедиаторов, на процессы нейрогенеза и нейропластичности, на работу оси ГГН и др., обладают также и противовоспалительной и иммуномодулирующей активностью, и, в частности, способностью снижать плазменные уровни таких воспалительных цитокинов, как ФНО- $\alpha$, ИЛ-1, ИЛ-6, ИЛ-8, ИЛ-17А, и значительно повышать уровень в плазме мощного противовоспалительного цитокина ИЛ-10 [Maes $\mathrm{M}$ et al, 2005]. Между тем, кишечные АБ, пребиотики и пробиотики также обладают сходным с АД воздействием на цитокиновый профиль крови, то есть, в частности, способностью повышать уровень в плазме ИЛ-10 и снижать уровни ФНО- $\alpha$, ИЛ-1, ИЛ-6, ИЛ-8, ИЛ-17А [Levkovich T et al, 2013]. В частности, плазменный уровень ИЛ-10 значительно повышался у животных, которым давали лактобактерии рамнозус штамма GG [Kopp MV et al, 2008].

Таким образом, совокупные данные экспериментов на животных и клинических результатов применения кишечных АБ, пребиотиков и пробиотиков при депрессивных и тревожных состояниях позволяют предположить, что их благоприятное воздействие на проявления тревоги и депрессии может обуславливаться конкуренцией пробиотиков с грамотрицательными микроорганизмами в кишечнике или уничтожением оных кишечными АБ, улучшением барьерной функции толстой кишки, 
снижением уровней воспалительных цитокинов и повышением противовоспалительных, что, в свою очередь, вторично приводит к улучшению баланса нейромедиаторов в ЦНС, нормализации работы оси ГГН и к улучшению настроения и самочувствия, снижению тревожности [Vlainić JV et al, 2016].

Ещё в 2013 году, готовя нашу книгу о терапевтически резистентных депрессиях, мы отмечали, что на ряде сайтов клиник так называемой «альтернативной медицины» в качестве одного из средств лечения депрессивных состояний, а также таких аллергических заболеваний, как экзема, и некоторых аутоиммунных заболеваний, широко рекламируется так называемая гидроколонотерапия (ГКТ). При этом мы отметили, что доказательной базы по её применению при депрессиях в доступных нам научных источниках в PubMed нам найти не удалось, однако отзывы пациентов свидетельствуют о её возможной эффективности [Быков ЮВ с соавт, 2013]. В свете новых научных данных, эффективность ГКТ при депрессиях, аутоиммунных и аллергических заболеваниях, вероятно, следует связывать не с самой процедурой ГКТ, а с обычно производимым после окончания промывания кишечника введением взвеси пробиотиков непосредственно в толстую кишку, и с предписываемым врачами этих клиник после завершения курса ГКТ приёмом пробиотиков внутрь и в свечах.

\section{Трансплантация фекальной микробиоты}

Трансплантация фекальной микробиоты (ТФМ) - это новый, экспериментальный метод лечения колопроктологических заболеваний, таких, как хроническая рецидивирующая инфекция Clostridium difficile [Ooijevaar RE et al, 2018], СРК [Juncadella AC, Moss A, 2017], различные ВБК (НЯК, БК) [Nishida A et al, 2017], хронические запоры [Zhang X et al, 2017], и др. В отличие от применения пробиотиков, содержащих только определённые штаммы «полезных» кишечных бактерий, при ТФМ производится пересадка сразу всего донорского микробиома, вместе с его естественными бактериофагами, а также вместе с ростовыми факторами бактерий, желчными кислотами и секреторными иммуноглобулинами (IgA), содержащимися в кале здорового донора или нескольких здоровых доноров. Предполагается, что это обеспечивает более высокую эффективность такой процедуры, по сравнению с применением изолированных пробиотиков, и более высокую приживляемость донорского микробиома по сравнению с приживляемостью культур пробиотиков. И действительно, при лечении, например, хронической рецидивирующей инфекции Clostridium difficile, эффективность 
ТФМ составляет до 95-98\%, и превышает эффективность ванкомицина, в силу чего этот метод даже предложено считать терапией первой линии для данной инфекции [Ooijevaar RE et al, 2018].

Процедура ТФМ состоит из двух фаз. Сначала в течение 1-2 недель проводится стерилизация кишечника реципиента с помощью приёма внутрь плохо абсорбируемых кишечных антибиотиков (рифаксимин, неомицин, в случае Clostridium difficile - ванкомицин с метронидазолом и др.) и/или систематического применения сильных слабительных и клизм в сочетании с диетой. Затем больному в прямую кишку (при помощи клизмы) или непосредственно в толстую кишку (через колоноскоп), или через назогастральный или назодуоденальный зонд в желудок или в двенадцатиперстную кишку вводится гомогенизированная суспензия или фильтрат донорского кала. Нередко для успешного приживления донорского микробиома и оказания терапевтического эффекта требуется не одна, а несколько процедур ТФМ, проводимых после первичной стерилизации кишечника с некоторым интервалом, особенно при ВБК [Nishida A et al, 2017].

В последнее время учёные стали проявлять большой интерес и к применению процедуры ТФМ при внекишечных заболеваниях, в частности, психических и неврологических, как потенциально более эффективного по сравнению с пробиотиками метода. Так, показана высокая эффективность ТФМ в уменьшении аутистической симптоматики у больных с РАС [Rosenfeld CS, 2015; Mangiola F et al, 2016], в уменьшении симптоматики СДВГ [Petra AI et al, 2015], депрессивных и тревожных проявлений у больных с депрессивными и тревожными расстройствами, в преодолении резистентности к АД при резистентных формах этих расстройств [Mangiola $\mathrm{F}$ et al, 2016], а также в улучшении моторики и торможении прогрессирования болезни Паркинсона, болезни Альцгеймера, рассеянного склероза и других нейродегенеративных заболеваний [Parashar A, Udayabanu M, 2017].

Интересно, что в экспериментах на мышах показано, что трансплантация фекальной микробиоты от депрессивных и тревожных больных в стерильный кишечник мышей и крыс приводит, наоборот, к развитию у них депрессивных и тревожных состояний и к ухудшению их интеллекта и социального взаимодействия, а повторная стерилизация кишечника животных с помощью АБ и последующая пересадка им здоровой фекальной микрофлоры от здоровых людей или животных приводит к купированию у них депрессии и тревоги, к улучшению их когнитивных функций и социального взаимодействия [Kelly JR et al, 2016]. 
Более того, показано, что ТФМ также может быть эффективна в лечении дислипидемии, ожирения и метаболического синдрома, часто встречающихся у психически больных [Kang Y, Cai Y, 2017], в лечении артериальной гипертензии и других сердечно-сосудистых заболеваний [Li J et al, 2017], СД 2-го типа [Kootte RS et al, 2017]. Верно, однако, и обратное: описан интересный клинический случай резкой прибавки массы тела и развития ожирения при случайной пересадке кала от донора с избыточным весом больному с колопроктологическим заболеванием [Kang Y, Cai Y, 2017].

Таким образом, ТФМ может представлять собой новый, перспективный, потенциально высокоэффективный (и потенциально более эффективный, чем изолированное применение пребиотиков, пробиотиков и/ или кишечных АБ) метод лечения психических и неврологических заболеваний, в том числе являющихся темой данной статьи - депрессивных и тревожных состояний, а также метод коррекции сопутствующих им эндокринно-обменных и сердечно-сосудистых нарушений.

Завершая обзор литературы о двусторонней связи колопроктологических заболеваний с тревожными и депрессивными состояниями, мы хотим представить два клинических случая из нашей практики, в которых ремиссия тревожно-депрессивного состояния, считавшегося терапевтически резистентным, наступила только после успешного лечения коморбидных колопроктологических заболеваний.

\section{Представление клинических случаев}

\section{Клинический случай 1.}

\section{Псевдорезистентная депрессия, коморбидная с хроническими} запорами, геморроем, ожирением и гипотиреозом

Пациент Н.С., 22 лет, обратился по поводу многолетнего (по его словам, с 14 лет) хронического депрессивного состояния, плохо поддающегося терапии. Ранее обращался к психиатрам и психотерапевтам, получал назначения антидепрессивных дозировок сульпирида (до 200 мг/сут), флупентиксола (до 3 мг/сут), а также различные СИОЗС - эсциталопрам (до 20 мг/сут), сертралин (до 200 мг/сут), без какого-либо заметного эффекта. Пациент предъявлял жалобы на выраженную вялость, апатию, отсутствие энергии, мотивации к учёбе и работе (пациент не работал, учился сугубо формально, результаты экзаменов «покупал»), слабость, вынуждающую много времени проводить в постели, на проблемы с кон- 
центрацией внимания и умственной продуктивностью, исключающие для него возможность успешной защиты диплома. На момент обращения пациент получал рекомендованную известным онлайн-консультантом доктором Горбатовым схему из 300 мг/сут пролонгированного венлафаксина (Велафакс МВ 150 мг 2 раза в день) и 300 мг/сут пролонгированного бупропиона (Элонтрил, заказан и получен пациентом из-за границы), с минимальным эффектом.

При расспросе выяснилось, что в 16-летнем возрасте у пациента обнаружили увеличение щитовидной железы и доброкачественные узелки в ней, чрезвычайно высокий титр антител АТ-ТПО. При этом уровень ТТГ составлял 6,5, а уровень свободного Т4 был чуть ниже нижней границы нормы. Однако впоследствии ТТГ пациента самостоятельно «вошёл в границы нормы» (стал ниже 4,0). В связи с этим эндокринолог не стал назначать пациенту заместительную терапию, несмотря на высокий титр АТ-ТПО, увеличение щитовидной железы и наличие симптомов, указывающих на клинически значимый гипотиреоз.

Затем выяснилось, что пациент с 14 лет - с того же времени, как появились первые признаки депрессивного состояния - страдает упорными хроническими запорами, осложнившимися тяжёлым (4-я степень) геморроем и страхом перед процессом дефекации. Как описывал пациент, «после дефекации приходится минимум полчаса лежать задом кверху, чтобы узлы можно было вправить». Лечения по этому поводу пациент не получал, к проктологам не обращался из-за стеснения, самостоятельно пользовался различными мазями и свечами, получая от этого кратковременное облегчение. При анализе кала на дисбактериоз, на который он был направлен нами, было обнаружено резко сниженное количество бифидо- и лактобактерий и избыточное размножение стрептококка. Пациент также страдал избыточным весом (108 кг при росте 184 см).

Пациенту была объяснена важность заместительной терапии гипотиреоза, коррекции хронических запоров, дисбактериоза, устранения геморроидальных кровотечений и связанных с ними хронических болей и потерь железа, а также важность похудания для успешного лечения депрессивного состояния. Затем пациенту была назначена заместительная терапия левотироксином (Эутирокс) с постепенным доведением дозы до 150 мкг/сут под контролем показателей ТТГ и свободного $\mathrm{T}_{4}$, длительный приём пробиотиков (Линекс). Рекомендована противозапорная диета с повышенным количеством клетчатки и других растительных волокон, растительного масла, дополнительный приём омега-3 полиненасыщен- 
ных жирных кислот и препаратов магния, обладающих, наряду с антидепрессивными, также лёгкими слабительными свойствами, увеличение потребления воды, ограничение потребления пряностей и соли, могущих вызвать обострение геморроя.

Для похудания пациенту был назначен метформин с постепенным доведением дозы до 2000 мг/сут, наряду с увеличением физической активности и снижением общей калорийности диеты.

По поводу наличия геморроя 4-й степени рекомендована консультация проктолога. После неё пациент получил оперативное лечение геморроя (клипирование).

Вышеописанный комплекс мер привёл к формированию терапевтической ремиссии депрессивного состояния, впервые за 8 лет лечения. Пациент успешно защитил диплом, работает по специальности, похудел со 108 до 85 кг, перестал испытывать страх перед дефекацией.

\section{Клинический случай 2.}

\section{Псевдорезистентная депрессия, коморбидная}

с болезнью Крона, осложнивиейся синдромом мальабсорбции и витамин $B_{12}$-дефицитной полинейропатией

Пациент А.К., 26 лет, первоначально обратился в чат кардиологов в Telegram по поводу хронической одышки, экстрасистол («перебоев в сердце») и постоянной тахикардии. Сочтён кардиологами по результатам расспроса ипохондриком, направлен ими на консультацию к одному из авторов настоящей статьи.

При сборе анамнеза выяснилось, что пациент с 20 лет страдает тревожно-депрессивным состоянием, включающим в себя как симптомы депрессии (вялость, апатию, сонливость, ангедонию, ограничение инициативы, интересов, мотивации), так и симптомы тревожности (ПА, плохой сон, «неуютно себя чувствует в социальных ситуациях», «постоянно грызут тревожные мысли»). Пациент также пожаловался на то, что «очень худой и никак не может набрать вес». Выяснилось, что он весит 45 (!) кг при росте 180 см. По поводу тревожности и депрессии обращался к психиатрам и психотерапевтам, получал назначения различных АД и анксиолитиков, малые дозы АП - флувоксамин до 200 мг/сут, эсциталопрам до $20 \mathrm{мг/сут,} \mathrm{сертралин} \mathrm{до} 150$ мг/сут, амитриптилин 50 мг/сут, сульпирид до 200 мг/сут, феназепам до 3 мг/сут, буспирон до 30 мг/сут, с минимальным эффектом. Разочаровался в психотропной терапии, на момент обращения ничего из психотропных препаратов не получал. 
При опросе на предмет наличия коморбидных заболеваний выяснилось, что у пациента с того же возраста (20 лет) диагностировано ВБК, которое, по его словам, «гистологически не могут дифференцировать - то ли БК, то ли НЯК». Заболевание течёт достаточно тяжело, сопровождается чередованием запоров и частых поносов, кровотечениями из ТК, болевым синдромом в животе и ПК. Несмотря на тяжесть течения, гастроэнтерологами и проктологами данному пациенту был назначен только месалазин (салофальк) 400 мг 3 раза в сутки, который пациент к тому же самовольно прекратил принимать, «потому что всё равно не помогает».

По словам пациента, «Ремикейд давать отказались, потому что он по квоте и положен только больным с тяжёлой формой БК, а у меня до сих пор не ясно, то ли это БК, то ли НЯК. А цитостатиками наши местные врачи пользоваться не умеют и боятся».

При дальнейшем расспросе выяснилось, что пациент с 12 лет веган по убеждениям, не ест мяса, яиц, рыбы и даже молочных продуктов. С момента развития БК пациент вообще соблюдает очень своеобразную и ограниченную диету, опасаясь обострения БК, и дополняет её искусственными аминокислотными смесями. Далее обнаружилось, что у пациента имеются периодические стреляющие боли по ходу нервных стволов, плексит, который он связывал с работой за компьютером и недостаточно эргономичной мышкой.

В ОАК - макроцитарная анемия, гемоглобин 86 г/л. Уровень витамина $\mathrm{B}_{12}$ в плазме пациента оказался чрезвычайно низким $(<125$ пг/мл по данным Инвитро, т.е. ниже порога детекции лаборатории). Также были обнаружены лабораторные признаки дефицита железа в крови, дефицит цинка и меди в волосах.

Пациент направлен на консультацию в Москву к хорошо знакомым автору иммунологу-аллергологу и гастроэнтерологу. Гастроэнтерологом проведено стационарное парентеральное питание, коррекция сопутствующего дисбактериоза кишечника, назначена заместительная терапия витамином $\mathrm{B}_{12}$ внутримышечно, препараты железа, цинка, меди в дополнение к приёму обычных поливитаминов.

Иммунологом, после коррекции гастроэнтерологом состояния питания пациента и улучшения его соматического статуса, нормализации показателей ОАК, назначено активное иммуносупрессивное лечение: пульс-терапия (3 инфузии циклофосфамида 1000 мг/сут в комбинации с метилпреднизолоном 1000 мг/сут с интервалом 28 дней), с последующим переводом на поддерживающую терапию месалазином (400 мг 4 раза в сутки) в комбинации с постепенно снижающимися дозами метилпредни- 
золона (с 40 мг/сут вначале, до нуля в настоящее время) и азатиоприном 50 мг/сут под контролем ОАК. В дальнейшем пациенту при помощи упомянутого специалиста удалось получить квоту на Ремикейд, который был добавлен к терапии.

На этом фоне, после стабилизации БК, достижения её ремиссии, назначение пациенту всего 50 мг/сут сертралина в сочетании с когнитивно-поведенческой психотерапией, привело к становлению ремиссии тревожно-депрессивного состояния. Пациент впервые за 6 лет болезни смог перейти от фриланса (работы дома) к постоянной занятости в офисе (он программист), социализироваться. Масса тела в настоящее время составляет около 60 кг, признаков мальабсорбции питательных веществ нет.

\section{Заключение}

Как видно из приведённых нами данных литературы и описания клинических случаев, многие колопроктологические заболевания тесно ассоциируются с развитием при них коморбидных депрессивных состояний или усугублением уже имеющихся депрессий, с формированием терапевтической резистентности депрессий. Для некоторых таких ассоциаций даже известны и описаны предполагаемые общие патофизиологические механизмы, объясняющие эту связь. Важно то, что при многих колопроктологических заболеваниях, например, ВЗК, РПТК, геморрое, хронических запорах, анальных трещинах, наличие коморбидной депрессии ассоциируется с худшим прогнозом заболевания, более агрессивным его течением, более высокой частотой обострений и рецидивов, осложнений, с худшим ответом на терапию. И наоборот - своевременное выявление и активное лечение сопутствующей депрессии доказанно улучшает прогноз основного колопроктологического заболевания и результаты его лечения, а также общее качество жизни больных.

В свете этого необходимо повышение квалификации колопроктологов в области своевременного выявления у их больных коморбидной депрессивной симптоматики, систематическое использование скрининговых шкал на депрессию и тревогу (например, простейшей шкалы PHQ-9) у колопроктологических больных, а также улучшение взаимодействия колопроктологов с психиатрами и психотерапевтами, и своевременное направление ими нуждающихся в этом больных на консультацию к психиатру и/или психотерапевту.

Верно и обратное: депрессивные состояния статистически достоверно ассоциируются с развитием при них хронических запоров (собственно, это 
типичный соматовегетативный симптом депрессии), а также с повышенным риском развития РПТК и ВЗК, СРК, геморроя, анальных трещин, дисбактериоза кишечника, и некоторых других колопроктологических заболеваний, и с ухудшением течения уже имеющихся у больного коморбидных колопроктологических заболеваний. Некоторые колопроктологические заболевания, например, РПТК или хронические запоры, ВЗК, дисбактериоз кишечника, даже ассоциируются с возникновением резистентности депрессии к АД, или могут лежать в основе патогенеза депрессии (как в случае дисбактериоза кишечника). И наоборот, эффективное лечение сопутствующего колопроктологического заболевания (например, устранение хронического запора, дисбактериоза кишечника, ликвидация воспаления и нормализация цитокинового профиля при ВЗК, достижение ремиссии РПТК) достоверно улучшает прогноз лечения депрессии.

Важно помнить и о том, что ряд психотропных препаратов способны вызывать запоры или поносы, и что эти ПЭ не являются безобидными и могут привести к развитию таких вторичных колопроктологических осложнений, как геморрой или анальные трещины, а также к снижению приверженности больного к лечению, преждевременному прекращению или отказу от лечения, или к развитию резистентности депрессии к АД вследствие связанной с запорами хронической каловой интоксикации, дисбактериоза кишечника и других факторов.

В свете этого необходимо повышение квалификации психиатров и психотерапевтов в отношении возможной связи депрессивных состояний и их психотропного лечения с колопроктологическими заболеваниями, важности их своевременного выявления и устранения, улучшение взаимодействия психиатров и психотерапевтов с колопроктологами, и своевременное направление нуждающихся в этом больных к колопроктологам. Следует учитывать, что депрессивные больные нередко стесняются самостоятельно озвучивать наличие у них таких проблем, как хронические запоры или поносы, хроническая аноректальная боль или зуд, геморрой или анальная трещина, выделение крови при дефекации. Поэтому важно эксплицитно задавать соответствующие вопросы для выявления среди депрессивных больных тех, кто нуждается также в консультации колопроктолога.

\section{Сиисок литературы / References}

1. Быков Ю.В., Беккер Р.А., Резников М.К. Депрессии и резистентность (практическое руководство). М.: ИНФРА-М., 2013. 
2. Abautret-Daly Á. et al. Gut-brain actions underlying comorbid anxiety and depression associated with inflammatory bowel disease //Acta Neuropsychiatrica. 2017. C. 1-22.

3. Abdel-Salam O.M.E., Baiuomy A.R., Arbid M.S. Studies on the anti-inflammatory effect of fluoxetine in the rat //Pharmacological Research. 2004. T. 49. №. 2. C. 119-131.

4. Addolorato G. et al. Inflammatory bowel disease: a study of the association between anxiety and depression, physical morbidity, and nutritional status // Scandinavian journal of gastroenterology. 1997. T. 32. №. 10. C. 1013-1021.

5. Akil H. et al. Tropomyosin-related kinase B/brain derived-neurotrophic factor signaling pathway as a potential therapeutic target for colorectal cancer//World journal of gastroenterology. 2016. T. 22. №. 2. C. 490-500.

6. Allen-Mersh T.G. et al. Relation between depression and circulating immune products in patients with advanced colorectal cancer//Journal of the Royal Society of Medicine. 1998. T. 91. №. 8. C. 408-413.

7. Archer J.A. et al. Interrelationship of depression, stress and inflammation in cancer patients: a preliminary study //Journal of affective disorders. 2012. T. 143. №. 1. C. 39-46.

8. Aricioğlu F. et al. Evaluation of antinociceptive and anti-inflammatory effects of venlafaxine in the rat //Agri: Agri (Algoloji) Dernegi'nin Yayin organidir= The journal of the Turkish Society of Algology. 2005. T. 17. №. 4. C. 41-46.

9. Arısoy Ö., Şengül N., Çakir A. Stress and psychopathology and its impact on quality of life in chronic anal fissure (CAF) patients //International journal of colorectal disease. 2017. T. 32. №. 6. C. 921-924.

10. Atkin G.K., Suliman A., Vaizey C.J. Patient characteristics and treatment outcome in functional anorectal pain //Diseases of the Colon \& Rectum. 2011. T. 54. №. 7. C. $870-875$.

11. Battaglia T.A. et al. Beliefs About Anal Cancer among HIV-Infected Women: Barriers and Motivators to Participation in Research //Women's Health Issues. 2015. T. 25. №. 6. C. 720-726.

12. Beck D.E. et al. (ed.). The ASCRS textbook of colon and rectal surgery. Springer Science \& Business Media, 2011.

13. Benedict C. et al. Investigation of body image as a mediator of the effects of bowel and GI symptoms on psychological distress in female survivors of rectal and anal cancer //Supportive Care in Cancer. 2016. T. 24. №. 4. C. 1795-1802.

14. Bentzen A.G. et al. Impaired health-related quality of life after chemoradiotherapy for anal cancer: late effects in a national cohort of 128 survivors //Acta Oncologica. 2013. T. 52. №. 4. C. 736-744. 
15. Bogaczewicz J. et al. Exacerbations of bipolar disorder triggered by chloroquine in systemic lupus erythematosus - a case report //Lupus. 2014. T. 23. №. 2. C. 188-193.

16. Borre Y.E. et al. Microbiota and neurodevelopmental windows: implications for brain disorders //Trends in molecular medicine. 2014. T. 20. №. 9. C. 509518.

17. Bosma E. et al. Health status, anxiety, and depressive symptoms following complicated and uncomplicated colorectal surgeries // International journal of colorectal disease. 2016. T. 31. №. 2. C. 273-282.

18. Bottino S. M. B., Fráguas R., Gattaz W.F. Depression and cancer //Archives of Clinical Psychiatry (São Paulo). 2009. T. 36. C. 109-115.

19. Bouchoucha M., Devroede G., Arsac M. Anismus: a marker of multi-site functional disorders? //International journal of colorectal disease. 2004. T. 19. №. 4. C. 374-379.

20. Bruce-Keller A. J., Salbaum J. M., Berthoud H. R. Harnessing Gut Microbes for Mental Health: Getting From Here to There //Biological psychiatry. 2017. pii: S0006-3223(17)31902-9.

21. Canli T. Reconceptualizing major depressive disorder as an infectious disease //Biology of mood \& anxiety disorders. 2014. T. 4. №. 1. C. 10.

22. Carmack C. L. et al. Feasibility of an expressive $\square$ disclosure group intervention for post-treatment colorectal cancer patients //Cancer. 2011. T. 117. №. 21. C. 4993-5002.

23. Cioli V. M., Gagliardi G., Pescatori M. Psychological stress in patients with anal fistula //International journal of colorectal disease. 2015. T. 30. №. 8. C. $1123-1129$.

24. de Farias C. B. et al. BDNF/TrkB signaling protects HT-29 human colon cancer cells from EGFR inhibition // Biochemical and biophysical research communications. 2012. T. 425. №. 2. C. 328-332.

25. de Oliveira Ribeiro N. P. et al. Anxiety, depression and suicidal ideation in patients with rheumatoid arthritis in use of methotrexate, hydroxychloroquine, leflunomide and biological drugs // Comprehensive psychiatry. 2013. T. 54. №. 8. C. $1185-1189$.

26. De Winter B. Y. et al. Effect of ghrelin and growth hormone-releasing peptide 6 on septic ileus in mice //Neurogastroenterology \& Motility. 2004. T. 16. №. 4. C. 439-446.

27. Del Popolo F. et al. Psycho-echo-biofeedback: a novel treatment for anismus results of a prospective controlled study // Techniques in coloproctology. 2014. T. 18. №. 10. C. 895-900. 
28. Deter H. C. et al. High-utilizing Crohn's disease patients under psychosomatic therapy //BioPsychoSocial medicine. 2008. T. 2. №. 1. C. 18.

29. Devanarayana N. M. et al. Abdominal pain-predominant functional gastrointestinal diseases in children and adolescents: prevalence, symptomatology, and association with emotional stress //Journal of pediatric gastroenterology and nutrition. 2011. T. 53. №. 6. C. 659-665.

30. Drossman D. A. et al. Psychosocial aspects of the functional gastrointestinal disorders // Gut. 1999. T. 45. №. suppl 2. C. II25-II30.

31. Dunn J. et al. Dimensions of quality of life and psychosocial variables most salient to colorectal cancer patients // Psycho-Oncology. 2006. T. 15. №. 1. C. $20-30$.

32. Elderon L., Whooley M. A. Depression and cardiovascular disease //Progress in cardiovascular diseases. 2013. T. 55. №. 6. C. 511-523.

33. Emmanuel A., Quigley E. M. M. (ed.). Irritable bowel syndrome: diagnosis and clinical management. John Wiley \& Sons, 2013.

34. Emmertsen K. J., Laurberg S. Impact of bowel dysfunction on quality of life after sphincter $\square$ preserving resection for rectal cancer //British Journal of Surgery. 2013. T. 100. №. 10. C. 1377-1387.

35. Eshuis E. J. et al. Suicide attempt in ulcerative colitis patient after 4 months of infliximab therapy - a case report // Journal of Crohn's and Colitis. 2010. T. 4. №. 5. C. 591-593.

36. Evrensel A., Ceylan M. E. The Gut-Brain Axis: The Missing Link in Depression //Clinical psychopharmacology and neuroscience: the official scientific journal of the Korean College of Neuropsychopharmacology. 2015. T. 13. №. 3. C. 239-244.

37. Filipovic B. R., Filipovic B. F. Psychiatric comorbidity in the treatment of patients with inflammatory bowel disease // World journal of gastroenterology. 2014. T. 20. №. 13. C. 3552-3563.

38. Fingeret M. C., Teo I., Epner D. E. Managing body image difficulties of adult cancer patients: lessons from available research // Cancer. 2014. T. 120. №. 5. C. 633-641.

39. Fitzgerald P. et al. Tryptophan catabolism in females with irritable bowel syndrome: relationship to interferon-gamma, severity of symptoms and psychiatric co-morbidity //Neurogastroenterology \& Motility. 2008. T. 20. №. 12. C. 1291-1297.

40. Fletcher B. C. et al. Eating disorders and concurrent psychopathology: a reconceptualisation of clinical need through Rasch analysis //European Eating Disorders Review. 2008. T. 16. №. 3. C. 191-198. 
41. Ghia J. E., Blennerhassett P., Collins S. M. Impaired parasympathetic function increases susceptibility to inflammatory bowel disease in a mouse model of depression //The Journal of clinical investigation. 2008. T. 118. №. 6. C. 2209-2218.

42. Good M. I., Shader R. I. Lethality and behavioral side effects of chloroquine // Journal of clinical psychopharmacology. 1982. T. 2. №. 1. C. 40-47.

43. Graff L. A., Walker J. R., Bernstein C. N. Depression and anxiety in inflammatory bowel disease: a review of comorbidity and management //Inflammatory bowel diseases. 2009. T. 15. №. 7. C. 1105-1118.

44. Grano C. et al. Feelings of depression in people with arm: The role of critical incidents and perceived difficulties in close and sexual relationships //Pediatric surgery international. 2014. T. 30. №. 8. C. 823-828.

45. Greenbaum D. S. et al. Effects of desipramine on irritable bowel syndrome compared with atropine and placebo //Digestive diseases and sciences. 1987. T. 32. №. 3. C. 257-266.

46. Griffiths C. E. M. et al. Impact of Ixekizumab Treatment on Depressive Symptoms and Systemic Inflammation in Patients with Moderate-to-Severe Psoriasis: An Integrated Analysis of Three Phase 3 Clinical Studies //Psychotherapy and psychosomatics. 2017. T. 86. №. 5. C. 260-267.

47. Gupta R. K. Major depression: an illness with objective physical signs //The World Journal of Biological Psychiatry. 2009. T. 10. №. 3. C. 196-201.

48. Hajhashemi V. et al. Central and peripheral anti-inflammatory effects of maprotiline on carrageenan-induced paw edema in rats //Inflammation research. 2010. T. 59. №. 12. C. 1053-1059.

49. Hariram J., Jegan Y. Contribution of methotrexate in precipitation of manic episode in bipolar affective disorder explored: a case report //Therapeutic advances in psychopharmacology. 2013. T. 3. №. 4. C. 251-254.

50. Hosseinzadeh S. T. et al. Psychological disorders in patients with chronic constipation // Gastroenterology and hepatology from bed to bench. 2011. T. 4. №. 3. C. 159-163.

51. Illman J. et al. Are inflammatory cytokines the common link between cancer-associated cachexia and depression?//Journal of Supportive Oncology. 2005. T. 3. №. 1. C. $37-50$.

52. Jain R., Jain S. Anti-depressants in the treatment of chronic pain //Pract Pain Manag. 2011. T. 11. C. 1-12.

53. Jia Y. et al. Depression and cancer risk: a systematic review and meta-analysis //Public health. 2017. T. 149. C. 138-148.

54. Juncadella A. C., Moss A. Fecal microbiota transplantation as a possible treatment of irritable bowel syndrome //Annals of translational medicine. 2017. T. 5. №. 24. C. 506. 
55. Kaidar-Person O., Person B., Wexner S. D. Hemorrhoidal disease: a comprehensive review //Journal of the American College of Surgeons. 2007. T. 204. №. 1. C. 102-117.

56. Kang Y., Cai Y. Gut microbiota and obesity: implications for fecal microbiota transplantation therapy //Hormones (Athens, Greece). 2017. T. 16. №. 3. C. 223-234.

57. Kappelmann N. et al. Antidepressant activity of anti-cytokine treatment: a systematic review and meta-analysis of clinical trials of chronic inflammatory conditions // Molecular psychiatry. 2016.

58. Kelly J. R. et al. Transferring the blues: depression-associated gut microbiota induces neurobehavioural changes in the rat // Journal of psychiatric research. 2016. T. 82. C. 109-118.

59. Kootte R. S. et al. Improvement of insulin sensitivity after lean donor feces in metabolic syndrome is driven by baseline intestinal microbiota composition // Cell metabolism. 2017. T. 26. №. 4. C. 611-619. e6.

60. Kopp M. V. et al. Lactobacillus GG has in vitro effects on enhanced interleukin-10 and interferon- $\gamma$ release of mononuclear cells but no in vivo effects in supplemented mothers and their neonates //Clinical \& Experimental Allergy. 2008. T. 38. №. 4. C. 602-610.

61. Kukla U. et al. Mental disorders in digestive system diseases-internist's and psychiatrist's insight // Polski merkuriusz lekarski: organ Polskiego Towarzystwa Lekarskiego. 2015. T. 38. №. 227. C. 245-249.

62. Kurina L. M. et al. Depression and anxiety in people with inflammatory bowel disease // Journal of Epidemiology \& Community Health. 2001. T. 55. №. 10. C. $716-720$.

63. Levkovich T. et al. Probiotic bacteria induce a 'glow of health'//PloS one. 2013. T. 8. №. 1. C. e53867.

64. Li J. et al. Gut microbiota dysbiosis contributes to the development of hypertension // Microbiome. 2017. T. 5. №. 1. C. 14.

65. Livovsky D. M. et al. Tricyclic antidepressants for the treatment of tenesmus associated with rectal prolapse //Colorectal Disease. 2015. T. 17. №. 12. C. 1094-1099.

66. Lorenzo-Rivero S. Hemorrhoids: diagnosis and current management //The American surgeon. 2009. T. 75. №. 8. C. 635-642.

67. Ma M. et al. Effects of Brilliant Blue G on Serum Tumor Necrosis Factor- $\alpha$ Levels and Depression-like Behavior in Mice after Lipopolysaccharide Administration //Clinical psychopharmacology and neuroscience: the official scientific journal of the Korean College of Neuropsychopharmacology. 2014. T. 12. №. 1. C. 31-36. 
68. Maes M. et al. The negative immunoregulatory effects of fluoxetine in relation to the cAMP-dependent PKA pathway //International immunopharmacology. 2005. T. 5. №. 3. C. 609-618.

69. Magni G. et al. Psychological findings in chronic anal pain //Psychopathology. 1986. T. 19. №. 4. C. 170-174.

70. Mangiola F. et al. Gut microbiota in autism and mood disorders //World Journal of Gastroenterology. 2016. T. 22. №. 1. C. 361-368.

71. Mapel D. W., Schum M., Von Worley A. The epidemiology and treatment of anal fissures in a population-based cohort // BMC gastroenterology. 2014. T. 14. №. 1. C. 129.

72. Massetti G. M. et al. Mental health problems and cancer risk factors among young adults //American journal of preventive medicine. 2017. T. 53. №. 3. C. S30-S39.

73. Mayer E. A. Gut feelings: the emerging biology of gut-brain communication // Nature Reviews Neuroscience. 2011. T. 12. №. 8. C. 453-466.

74. McNutt M. D. et al. Neurobehavioral effects of interferon- $\alpha$ in patients with hepatitis-C: symptom dimensions and responsiveness to paroxetine //Neuropsychopharmacology. 2012. T. 37. №. 6. C. 1444-1454.

75. Medeiros M., Oshima C. T. F., Forones N. M. Depression and anxiety in colorectal cancer patients //Journal of gastrointestinal cancer. 2010. T. 41. №. 3. C. $179-184$.

76. Mikocka-Walus A. et al. Symptoms of depression and anxiety are independently associated with clinical recurrence of inflammatory bowel disease //Clinical gastroenterology and hepatology. 2016. T. 14. №. 6. C. 829-835. e1.

77. Milne B., Joachim G., Niedhardt J. A stress management programme for inflammatory bowel disease patients //Journal of advanced nursing. 1986. T. 11. №. 5. C. 561-567.

78. Mittermaier C. et al. Impact of depressive mood on relapse in patients with inflammatory bowel disease: a prospective 18-month follow-up study //Psychosomatic medicine. 2004. T. 66. №. 1. C. 79-84.

79. Musselman D. L. et al. Higher than normal plasma interleukin-6 concentrations in cancer patients with depression: preliminary findings //American Journal of Psychiatry. 2001. T. 158. №. 8. C. 1252-1257.

80. Nashed M. G. et al. Behavioural Effects of Using Sulfasalazine to Inhibit Glutamate Released by Cancer Cells: A Novel target for Cancer-Induced Depression // Scientific reports. 2017. T. 7. C. 41382.

81. North C. S., Hong B. A., Alpers D. H. Relationship of functional gastrointestinal disorders and psychiatric disorders: implications for treatment //World journal of gastroenterology. 2007. T. 13. №. 14. C. 2020-2027. 
82. Nowakowski J., Chrobak A. A., Dudek D. Psychiatric illnesses in inflammatory bowel diseases-psychiatric comorbidity and biological underpinnings // Psychiatr. Pol. 2016. T. 50. №. 6. C. 1157-1166.

83. O'Mahony S. M. et al. 5-HT (2B) receptors modulate visceral hypersensitivity in a stress-sensitive animal model of brain-gut axis dysfunction //Neurogastroenterology and motility: the official journal of the European Gastrointestinal Motility Society. 2010. T. 22. №. 5. C. 573-578, e124.

84. O’Mahony S. M. et al. Early life stress alters behavior, immunity, and microbiota in rats: implications for irritable bowel syndrome and psychiatric illnesses //Biological psychiatry. 2009. T. 65. №. 3. C. 263-267.

85. Ooijevaar R. E. et al. Update of treatment algorithms for Clostridium difficile infection //Clinical Microbiology and Infection. 2018. pii: S1198743X(18)30021-1.

86. Parashar A., Udayabanu M. Gut microbiota: Implications in Parkinson's disease //Parkinsonism \& Related Disorders. 2017. T. 38. C. 1-7.

87. Persoons P. et al. The impact of major depressive disorder on the short $\square$ and long-term outcome of Crohn's disease treatment with infliximab //Alimentary pharmacology \& therapeutics. 2005. T. 22. №. 2. C. 101-110.

88. Petra A. I. et al. Gut-microbiota-brain axis and its effect on neuropsychiatric disorders with suspected immune dysregulation //Clinical therapeutics. 2015. T. 37. №. 5. C. 984-995.

89. Purim O., Gordon N., Brenner B. Cancer of the colon and rectum: potential effects of sex-age interactions on incidence and outcome //Medical science monitor: international medical journal of experimental and clinical research. 2012. T. 19. C. 203-209.

90. Pyter L. M. et al. Peripheral tumors induce depressive-like behaviors and cytokine production and alter hypothalamic-pituitary-adrenal axis regulation //Proceedings of the National Academy of Sciences. 2009. T. 106. №. 22. C. 9069 9074.

91. Rebrov V. G., Lukomskiı̌ M. I. A case of depression in the treatment of nonspecific ulcerative colitis with sulfasalazine//Klinicheskaia meditsina. 1989. T. 67. №. 8. C. 106.

92. Renzi C., Pescatori M. Psychologic aspects in proctalgia //Diseases of the colon \& rectum. 2000. T. 43. №. 4. C. 535-539.

93. Rich T. et al. Elevated serum cytokines correlated with altered behavior, serum cortisol rhythm, and dampened 24-hour rest-activity patterns in patients with metastatic colorectal cancer//Clinical cancer research. 2005. T. 11. №. 5. C. $1757-1764$. 
94. Rosenfeld C. S. Microbiome Disturbances and Autism Spectrum Disorders // Drug metabolism and disposition: the biological fate of chemicals. 2015. T. 43. №. 10. C. $1557-1571$.

95. Sadeghi H. et al. A study on the mechanisms involving the anti-inflammatory effect of amitriptyline in carrageenan-induced paw edema in rats //European journal of pharmacology. 2011. T. 667. №. 1. C. 396-401.

96. Sajadinejad M. S. et al. Psychological issues in inflammatory bowel disease: an overview //Gastroenterology research and practice. 2011. T. 2012. C. 106502.

97. Scarlett Y. Medical management of fecal incontinence//Gastroenterology. 2004. T. 126. C. S55-S63.

98. Scherer J. Depression induced by salazosulfapyridine in cyclothymia and Crohn disease //Der Nervenarzt. 1988. T. 59. №. 6. C. 371-373.

99. Sertbas Y. et al. Assesment of psychiatric symptoms and co-morbidities in patients with irritable bowel syndrome //West Indian Medical Journal. 2012. T. 61. №. 5. C. $544-548$.

100. Seruga B. et al. Cytokines and their relationship to the symptoms and outcome of cancer//Nature Reviews Cancer. 2008. T. 8. №. 11. C. 887-899.

101. Soares de Lima T. A. et al. Proinflammatory cytokines correlate with depression and anxiety in colorectal cancer patients //BioMed research international. 2014. T. 2014. C. 739650.

102. Späth-Schwalbe E. et al. Acute effects of recombinant human interleukin-6 on endocrine and central nervous sleep functions in healthy men //The Journal of Clinical Endocrinology \& Metabolism. 1998. T. 83. №. 5. C. 1573-1579.

103. Stahl S. M. Stahl's essential psychopharmacology: neuroscientific basis and practical applications. Cambridge university press, 2013.

104. Staller K. et al. Depression but Not Symptom Severity is Associated With Work and School Absenteeism in Refractory Chronic Constipation //Journal of clinical gastroenterology. 2017.

105. Taché Y., Bernstein C. N. Evidence for the role of the brain-gut axis in inflammatory bowel disease: depression as cause and effect? //Gastroenterology. 2009. T. 136. №. 7. C. 2058-2061.

106. Taché Y., Kiank C., Stengel A. A role for corticotropin-releasing factor in functional gastrointestinal disorders //Current gastroenterology reports. 2009. T. 11. №. 4. C. 270-277.

107. Tamaji A. et al. Differential effects of diazepam, tandospirone, and paroxetine on plasma brain-derived neurotrophic factor level under mental stress // Human Psychopharmacology: Clinical and Experimental. 2012. T. 27. №. 3. C. 329-333. 
108. Tanaka K. et al. Brain-derived neurotrophic factor (BDNF)-induced tropomyosin-related kinase B (Trk B) signaling is a potential therapeutic target for peritoneal carcinomatosis arising from colorectal cancer //PloS one. 2013. T. 9. №. 5. C. e96410.

109. Taylor C., Bradshaw E. Tied to the toilet: lived experiences of altered bowel function (anterior resection syndrome) after temporary stoma reversal //Journal of Wound Ostomy \& Continence Nursing. 2013. T. 40. №. 4. C. 415-421.

110. Teunissen S, da Graeff, Voest E. Are anxiety and depressed mood related to physical symptom: a study in hospitalized advanced cancer patients. Palliative Mdicine. 2007;21:341-346.

111. Thong MS, Mols F, Lemmens VE et al. Impact of preoperative radiotherapy on general and disease-specific health status of rectal cancer survivors: a population-based study. Int J Radiat Oncol Biol Phys. 2011;81:49-58.

112. Tsunoda A. et al. Anxiety, depression and quality of life in colorectal cancer patients //International journal of clinical oncology. 2005. T. 10. №. 6. C. 411-417.

113. Udina $\mathrm{M}$. et al. Interferon-induced depression in chronic hepatitis $\mathrm{C}$ : a systematic review and meta-analysis //The Journal of clinical psychiatry. 2012. T. 73. №. 8. C. 1128-1138.

114. Van Oudenhove L. et al. Determinants of symptoms in functional dyspepsia: gastric sensorimotor function, psychosocial factors or somatisation? //Gut. 2008. T. 57. №. 12. C. 1666-1673.

115. Vanuytsel T. et al. Psychological stress and corticotropin-releasing hormone increase intestinal permeability in humans by a mast cell-dependent mechanism //Gut. 2014. T. 63. №. 8. C. 1293-1299.

116. Vlainic J. et al. Probiotics as an adjuvant therapy in major depressive disorder //Current neuropharmacology. 2016. T. 14. №. 8. C. 952-958.

117. Wedding U. et al. Depression and functional impairment independently contribute to decreased quality of life in cancer patients prior to chemotherapy // Acta Oncologica. 2008. T. 47. №. 1. C. 56-62.

118. Wu S. F. et al. Symptom Distress, Depression, and Quality of Life in Colorectal Cancer Patients at Different Disease Stages //Hu li za zhi The journal of nursing. 2015. T. 62. №. 6. C. 68-80.

119. Zhang X. et al. Efficacy observation of periodic fecal microbiota transplantation in the treatment of refractory constipation //Zhonghua wei chang wai ke za zhi= Chinese journal of gastrointestinal surgery. 2017. T. 20. №. 12. C. $1355-1359$.

120. Zhou L. et al. Upregulation of blood proBDNF and its receptors in major depression //Journal of affective disorders. 2013. T. 150. №. 3. C. 776-784. 


\section{ДАННЫЕ ОБ АВТОРАХ}

Беккер Роман Александрович, магистр в области компьютерных наук, исследователь в области психофармакотерапии Университет им. Давида Бен-Гуриона в Негеве а/я 653, Беер-Шева, 8410501, Израиль rbekker1@gmail.com

Быков Юрий Витальевич, кандидат медицинских наук, ассистент кафедры анестезиологии, реаниматологии и скорой медицинской помощи Ставропольский Государственный Медицинский Университет ул. Мира, 310, г. Ставрополь, Ставропольский край, Российская Федераиия yubykov@gmail.com

\section{DATA ABOUT THE AUTHORS}

Bekker Roman Aleksandrovich, M.Sc., Researcher

Ben-Gurion University of the Negev

P.O.B. 653, Beer-Sheva, 8410501, Israel

rbekker1@gmail.com

ORCID: 0000-0002-0773-3405

ResearcherID: J-7724-2016

Bykov Yuriy Vitalevich, PhD, Assistant of the Department of Anesthesiology, Intensive Care and Emergency Medical Care Stavropol State Medical University 310, Mira Str., Stavropol, Russian Federation yubykov@gmail.com ORCID: 0000-0003-4705-3823

ResearcherID: K-1888-2016 